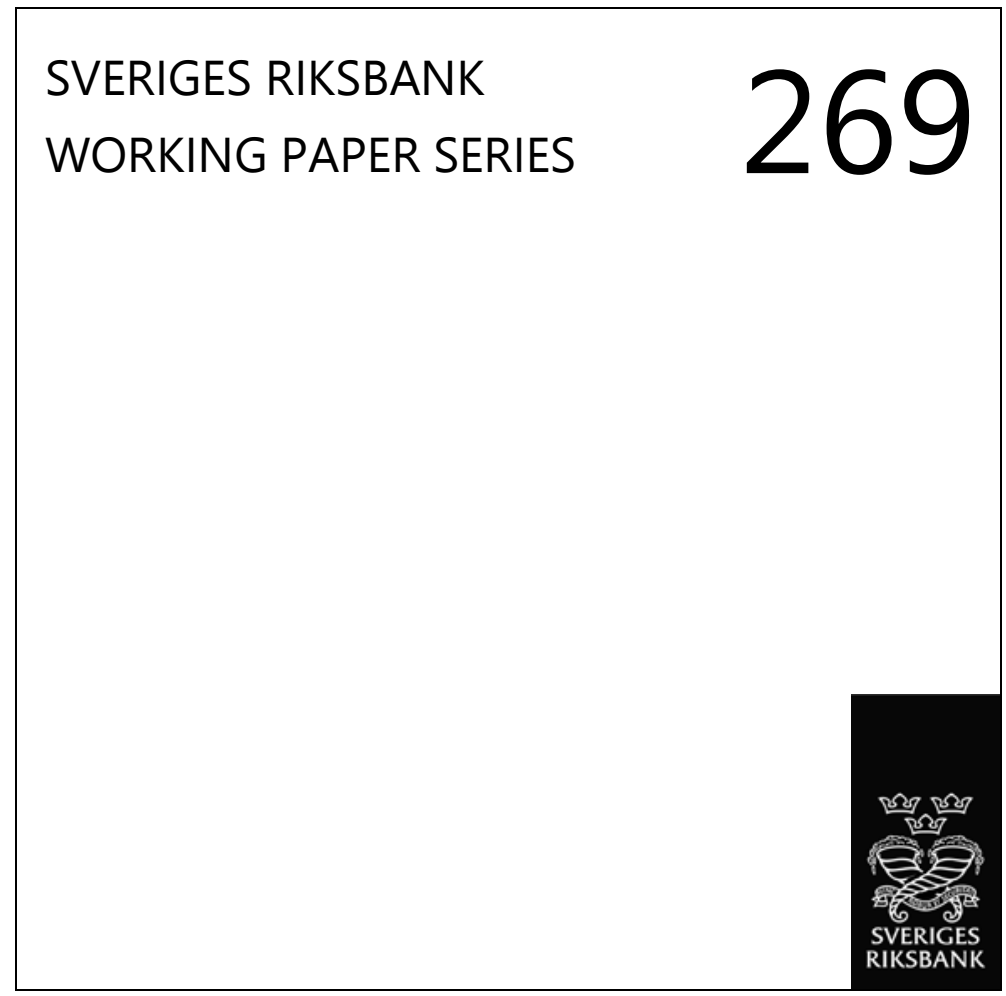

\title{
Conditional euro area sovereign default risk *
}

André Lucas, Bernd Schwaab and Xin Zhang

May 2013 


\section{WORKING PAPERS ARE OBTAINABLE FROM}

Sveriges Riksbank • Information Riksbank • SE-103 37 Stockholm

Fax international: +4687870526

Telephone international: +4687870100

E-mail: info@riksbank.se

The Working Paper series presents reports on matters in the sphere of activities of the Riksbank that are considered to be of interest to a wider public.

The papers are to be regarded as reports on ongoing studies and the authors will be pleased to receive comments.

The views expressed in Working Papers are solely the responsibility of the authors and should not to be interpreted as reflecting the views of the Executive Board of Sveriges Riksbank. 


\title{
Conditional euro area sovereign default risk ${ }^{*}$
}

\author{
André Lucas ${ }^{\dagger}$, Bernd Schwaab ${ }^{\ddagger}$, Xin Zhang $\$$ \\ Sveriges Riksbank Working Paper Series No. 269
}

May 2013

\begin{abstract}
We propose an empirical framework to assess the likelihood of joint and conditional sovereign default from observed CDS prices. Our model is based on a dynamic skewed-t distribution that captures all salient features of the data, including skewed and heavytailed changes in the price of CDS protection against sovereign default, as well as dynamic volatilities and correlations that ensure that uncertainty and risk dependence can increase in times of stress. We apply the framework to euro area sovereign CDS spreads during the euro area debt crisis. Our results reveal significant time-variation in distress dependence and spill-over effects for sovereign default risk. We investigate market perceptions of joint and conditional sovereign risk around announcements of Eurosystem asset purchases programs, and document a strong impact on joint risk.
\end{abstract}

Keywords: sovereign credit risk; higher order moments; time-varying parameters; financial stability.

JEL classifications: C32, G32.

${ }^{*}$ We thank seminar and conference participants at Bundesbank, HEC Lausanne, Riksbank, the RES meeting at Cambridge, the IRMC conference in Rome, the SoFiE conference in Oxford, the Econometric Society European Meeting in Malaga, the "Forecasting rare events" conference at San Francisco Fed, the Macro-prudential Research Network annual conference at ECB, the "New tools for financial regulation" conference at Banque de France, and the Humbold-Copenhagen Conference in Financial Econometrics in Berlin. André Lucas thanks the Dutch National Science Foundation (NWO) and the European Union Seventh Framework Programme (FP7-SSH/2007-2013, grant agreement 320270 - SYRTO) for financial support. The views expressed in this paper are solely the responsibility of the authors and should not be interpreted as reflecting the views of the Executive Board of Sveriges Riksbank, the European Central Bank, or the European System of Central Banks.

${ }^{\dagger}$ VU University Amsterdam and Tinbergen Institute, De Boelelaan 1105, 1081 HV Amsterdam, The Netherlands, Email: a.lucas@vu.nl.

${ }^{\ddagger}$ Financial Research, European Central Bank, Kaiserstrasse 29, 60311 Frankfurt, Germany, Email: bernd.schwaab@ecb.int.

${ }^{\S}$ Research Division, Sveriges Riksbank, Brunkebergstorg 11, SE 10337 Stockholm, Sweden, Email: xin.zhang@riksbank.se. 


\section{Introduction}

In this paper we construct a novel empirical framework to assess the likelihood of joint and conditional default on credit risky claims, such as government debt issued by euro area countries. This framework allows us to estimate marginal, joint, and conditional probabilities of a sovereign credit event from observed prices of credit default swaps (CDS) on sovereign debt. Default is defined as any credit event that would trigger a sovereign CDS contract, such as the non-payment of principal or interest when it is due, a forced exchange of debt into claims of lower value, a moratorium, or an official repudiation of the debt. Clearly, a risk assessment and monitoring framework is useful for tracking market perceptions about interacting sovereign risks during a debt crisis. However, the current framework should also be useful for market risk measurement of credit risky claims more generally.

Unlike marginal probabilities, conditional probabilities of sovereign default cannot be obtained from raw market data alone. Instead, they require a proper multivariate modeling framework. Our methodology is novel in that our joint and tail probability assessments are derived from a multivariate framework based on a dynamic Generalized Hyperbolic (GH) skewed- $t$ density that naturally accommodates all relevant empirical features of the data, such as skewed and heavy-tailed changes in individual country CDS spreads, as well as time variation in their volatilities and dependence. Moreover, the model can easily be calibrated to match current market expectations regarding the marginal probabilities of default as in for example Segoviano and Goodhart (2009), Huang, Zhou, and Zhu (2009), and Black, Correa, Huang, and Zhou (2012).

We make three empirical contributions in addition to introducing a novel non-Gaussian framework for modeling dependent risks. First, we provide estimates of the time variation in euro area joint and conditional sovereign default risk using a proposed model and a 10dimensional dataset of sovereign CDS spreads from January 2008 to February 2013. Using our results, we can investigate market perceptions regarding the conditional probability of 
a credit event in one country in the euro area given that a credit event occurs in another country. Such an analysis allows inference, for example, on which countries are considered by market participants to be more exposed to certain credit events than others. Our modeling framework also allows us to investigate the presence and severity of spill-overs in the risk of sovereign credit events as perceived by market participants. Specifically, we document spill-overs from the possibility of a credit event in one country to the perceived riskiness of other euro area countries. This suggests that, at least during a severe debt crisis, the cost of debt refinancing in one euro area country can depend on perceived developments in other countries. This, in turn, is consistent with a risk externality from public debt to other countries in a monetary union.

Second, we analyze the extent to which parametric modeling assumptions matter for joint and conditional risk assessments. Perhaps surprisingly, and despite the appeal of price-based joint risk measures to guide policy decisions and to evaluate their impact on credit markets ex post, we are not aware of a detailed investigation of how different parametric assumptions matter for joint and conditional risk assessments. We therefore report results based on a dynamic multivariate Gaussian, symmetric- $t$, and GH skewed- $t$ (GHST) specification, as well as a GHST copula approach. The distributional assumptions turn out to be most relevant for our conditional assessments, whereas simpler joint default probability estimates are less sensitive to the assumed dependence structure. In particular, and much in line with Forbes and Rigobon (2002), we show that it is important to account for the different salient features of the data, such as non-zero tail dependence and skewness, when interpreting estimates of time-varying volatilities and increases in correlation in times of stress.

Finally, we provide an in-depth analysis of the impact on sovereign risk of two key policy announcements made during the euro area sovereign debt crisis. First, on May 9, 2010, euro area heads of state announced a comprehensive rescue package to mitigate sovereign risk conditions and perceived risk contagion in the euro area. The rescue package contained the 
European Financial Stability Facility (EFSF), a rescue fund, and an asset purchase program (the Securities Markets Programme, SMP) within which the European Central Bank and 17 euro area national central banks would purchase government bonds in secondary markets. Later, on 02 August 2012, a second asset purchase program was announced (the Outright Monetary Transactions, OMT). The OMT replaced the earlier SMP. We assess joint and conditional sovereign default risk perceptions, as implied by CDS prices, around both policy announcements. For both the May 2010 and August 2012 announcements we find that market perceptions of joint sovereign default risk have decreased very strongly. In some cases joint bivariate risks decreased by more than $50 \%$ virtually overnight. We show that these strong reductions in joint risk were due to large reductions in marginal risk perceptions, while market perceptions of conditional sovereign default risk did not decrease at the same time. This suggests that perceived risk interactions remained a concern.

From a (tail) risk perspective, our joint approach is in line with for example Acharya, Pedersen, Philippon, and Richardson (2010) who focus on financial institutions: bad outcomes are much worse if they occur in clusters. What seems manageable in isolation may not be so if the rest of the system is also under stress. While adverse developments in one country's public finances or banking sectors could perhaps still be handled with the support of other non-distressed countries, the situation becomes more and more problematic if two, three, or more countries would be in distress. Relevant questions regarding joint and conditional sovereign default risk perceptions would be hard if not impossible to answer without an empirical model such as the one proposed in this paper.

The use of CDS data to estimate market implied default probabilities means that our probability estimates combine physical default probabilities with the price of sovereign default risk. As a result, our risk measures constitute an upper bound for an investor worried about loosing money due to joint sovereign defaults. This has to be kept in mind when interpreting the empirical results later on. Estimating default probabilities directly from 
observed defaults, however, is impossible in our context, as exactly one OECD default is observed over our sample period (Greece, on 08 March 2012). Even if more defaults would have been observed, they would not have allowed us to perform the detailed empirical analysis on the dynamics of joint and conditional default risk.

The literature on sovereign credit risk has expanded rapidly and branched off into different fields. Part of the literature focuses on the theoretical development of sovereign default risk and strategic default decisions; see for example Guembel and Sussman (2009), Yue (2010), and Tirole (2012). Another part of the literature tries to disentangle the different priced components of sovereign credit risk using asset pricing methodology, including the determination of common risk factors across countries; see for example Pan and Singleton (2008), Longstaff, Pan, Pedersen, and Singleton (2011), and Ang and Longstaff (2011). Benzoni, Collin-Dufresne, Goldstein, and Helwege (2011) and Caporin, Pelizzon, Ravazzolo, and Rigobon (2012a) model sovereign risk conditions in the euro area, and find evidence for risk contagion. Finally, the link between sovereign credit risk, country ratings, and macro fundamentals is investigated in for example Haugh, Ollivaud, and Turner (2009), Hilscher and Nosbusch (2010), and DeGrauwe and Ji (2012).

Our paper primarily relates to the empirical literature on sovereign credit risk as proxied by sovereign CDS spreads and focuses on spill-over risk as perceived by financial markets. We take a pure time-series perspective instead of assuming a specific pricing model as in Longstaff, Pan, Pedersen, and Singleton (2011) or Ang and Longstaff (2011). The advantage of such an approach is that we are much more flexible in accommodating all the relevant empirical features of CDS changes given that we are not bound by the analytical (in)tractability of a particular pricing model. This appears particularly important for the data at hand. In particular, our paper relates closely to the statistical literature for multiple defaults, such as for example Li (2001), Hull and White (2004) and Avesani, Pascual, and Li (2006). These papers, however, typically build on a Gaussian or sometimes symmetric 
Student $t$ dependence structure, whereas we impose a dependence structure that allows for non-zero tail dependence, skewness, and time variation in both volatilities and correlations. Our approach therefore also relates to an important strand of literature on modeling dependence in high dimensions, see for example Demarta and McNeil (2005), Chen, Härdle, and Spokoiny (2010), Christoffersen, Errunza, Jacobs, and Langlois (2011), Patton and Oh (2012,2013), Smith, Gan, and Kohn (2012), and Engle and Kelly (2012), as well as to a growing literature on observation-driven time varying parameter models, such as for example Patton (2006), Harvey (2010), and Creal, Koopman and Lucas (2011, 2013). Finally, we relate to the CIMDO framework of Segoviano and Goodhart (2009). This is based on a multivariate prior distribution, usually Gaussian or symmetric-t, that can be calibrated to match marginal risks as implied by the CDS market. Their multivariate density becomes discontinuous at so-called threshold levels: some parts of the density are shifted up, others are shifted down, while the parametric tails and extreme dependence implied by the prior remain intact at all times. Our model does not have similar discontinuities, while it allows for a similar calibration of default probabilities to current CDS spread levels.

The remainder of the paper is as follows. In Section 2, we introduce the multivariate statistical model and discuss the estimation of fixed and time varying parameters. We present our main empirical results on joint and conditional sovereign risk during the euro area debt crisis in Section 3. In Section 4, we discuss the risk impact of Eurosystem asset purchase program announcements. We conclude in Section 5. 


\section{Statistical model}

\subsection{The dynamic Generalized Hyperbolic Skewed $t$ distribution}

We consider an observed vector time series $y_{t} \in \mathbb{R}^{n}, t=1, \ldots, T$, of $n$ sovereign CDS spread changes, where

$$
y_{t}=\mu_{t}+L_{t} e_{t}=\mu_{t}+\left(\varsigma_{t}-\mu_{\varsigma}\right) L_{t} \mathcal{T} \gamma+\sqrt{\varsigma_{t}} L_{t} \mathcal{T} z_{t},
$$

with $\mu_{t} \in \mathbb{R}^{n}$ a vector of means and $\Sigma_{t}=L_{t} L_{t}^{\prime} \in \mathbb{R}^{n \times n}$ a covariance matrix; $e_{t}=\left(\varsigma_{t}-\right.$ $\left.\mu_{\varsigma}\right) \mathcal{T} \gamma+\sqrt{\varsigma_{t}} \mathcal{T} z_{t}$ a Generalized Hyperbolic Skewed $t$ (GHST) distributed random variable with zero mean, unit covariance matrix I, $\nu>4$ degrees of freedom, and skewness parameter $\gamma \in \mathbb{R}^{n} ; \varsigma_{t} \in \mathbb{R}_{+}$an inverse Gamma distributed random variable with parameters $(\nu / 2, \nu / 2)$, mean $\mu_{\varsigma}=\nu /(\nu-2)$, and variance $\sigma_{\varsigma}^{2}=2 \nu^{2} /\left((\nu-2)^{2}(\nu-4)\right) ; \mathcal{T}$ a matrix such that $\mathcal{T}^{\prime} \mathcal{T}=$ $\left(\mu_{\varsigma} \mathrm{I}+\sigma_{\varsigma}^{2} \gamma \gamma^{\prime}\right)^{-1}$; and $z_{t} \in \mathbb{R}^{n}$ a standard multivariate normal random variable, independent of $\varsigma_{t}$. The mean-variance mixture construction for $e_{t}$ in (1) reveals that clustering of CDS spread changes can be the result of (time-varying) correlations as captured by $L_{t}$, or of large realizations of the common risk factor $\varsigma_{t}$. Earlier applications of the GHST distribution to financial and economic data include, for example, Mencía and Sentana (2005), Hu (2005), Aas and Haff (2006), and Patton and Oh (2012). Alternative skewed $t$ distributions have been proposed as well, such as Branco and Dey (2001), Gupta (2003), Azzalini and Capitanio (2003), and Bauwens and Laurent (2005); see also the overview of Aas and Haff (2006). The advantage of the GHST distribution vis-à-vis these alternatives is that the generalized hyperbolic class of distributions links in more closely with the fat-tailed and skewed pricing models from the continuous-time finance literature.

In the remaining exposition, we set $\mu_{t}=0$. For $\mu_{t} \neq 0$, all derivations go through if $y_{t}$ is 
replaced by $y_{t}-\mu_{t}$. The conditional density of $y_{t}$ is given by

$$
\begin{aligned}
p\left(y_{t} \mid L_{t}, \gamma, \nu\right) & =\frac{\nu^{\frac{\nu}{2}} 2^{1-\frac{\nu+n}{2}}}{\Gamma\left(\frac{\nu}{2}\right) \pi^{\frac{n}{2}}\left|L_{t} \mathcal{T}\right|} \cdot \frac{K_{\frac{\nu+n}{2}}\left(\sqrt{d\left(y_{t}\right) \cdot\left(\gamma^{\prime} \gamma\right)}\right) e^{\gamma^{\prime}\left(L_{t} \mathcal{T}\right)^{-1}\left(y_{t}-\tilde{\mu}_{t}\right)}}{d\left(y_{t}\right)^{\frac{\nu+n}{4}} \cdot\left(\gamma^{\prime} \gamma\right)^{-\frac{\nu+n}{4}}}, \\
d\left(y_{t}\right) & =\nu+\left(y_{t}-\tilde{\mu}_{t}\right)^{\prime}\left(L_{t} \mathcal{T} \mathcal{T}^{\prime} L_{t}^{\prime}\right)^{-1}\left(y_{t}-\tilde{\mu}_{t}\right) \\
\tilde{\mu}_{t} & =-\mu_{\varsigma} L_{t} \mathcal{T} \gamma
\end{aligned}
$$

where $K_{a}(b)$ is the modified Bessel function of the second kind, and the matrix $L_{t}$ characterizes the time-varying covariance matrix $\Sigma_{t}=L_{t} L_{t}^{\prime}=D_{t} R_{t} D_{t}$, where $D_{t}$ is a diagonal matrix containing the time-varying volatilities of $y_{t}$, and $R_{t}$ is the time-varying correlation matrix.

The fat-tailedness and skewness of CDS data pose a challenge for standard dynamic specifications of volatilities and correlations, such as standard GARCH or DCC type dynamics, see Engle (2002). In the presence of fat tails, large values of $y_{t}$ occur regularly even if volatility is not changing rapidly. If not properly accounted for, such observations lead to biased estimates of the dynamic behavior of volatilities and joint failure probabilities. A direct way to link the distributional properties of $y_{t}$ to the dynamic behavior of $\Sigma_{t}, L_{t}, D_{t}$, and $R_{t}$ is given by the Generalized Autoregressive Score (GAS) framework of Creal, Koopman, and Lucas $(2011,2013)$. In the GAS framework for the fat-tailed GHST distribution with time-varying volatilities and correlations, observations $y_{t}$ that lie far from the bulk of the data automatically receive less impact on volatility and correlation dynamics than under the normality assumption. The same holds for observations in the left tail if $y_{t}$ is left-skewed. The intuition for this is clear: the effect of a large observation $y_{t}$ is partly attributed to the fat-tailed nature of $y_{t}$ and partly to a local increase of volatilities and/or correlations. In this way, the estimates of volatilities and correlations in the GAS framework based on the GHST become more robust to incidental influential observations, which are prevalent in the CDS data used in our empirical analysis. We refer to Creal et al. (2011) and Zhang et al. (2011) for more details. 
The GAS dynamics for $\Sigma_{t}$ are given by the following equations. We assume that the time-varying covariance matrix $\Sigma_{t}$ is driven by a number of unobserved dynamic factors $f_{t}$, such that $\Sigma_{t}=\Sigma\left(f_{t}\right)=L\left(f_{t}\right) L\left(f_{t}\right)^{\prime}=D\left(f_{t}\right) R\left(f_{t}\right) D\left(f_{t}\right)$. In our empirical application in Section 3, the number of factors equals the number of free elements in $\Sigma_{t}$. We can, however, also pick a smaller number of factors to obtain a 'factor GAS' model. The dynamics of $f_{t}$ are given by

$$
\begin{aligned}
f_{t+1} & =\omega+\sum_{i=1}^{p} A_{i} s_{t+1-i}+\sum_{j=1}^{q} B_{j} f_{t+1-j} ; \\
s_{t} & =\mathcal{S}_{t} \nabla_{t}, \quad \nabla_{t}=\partial \ln p\left(y_{t} \mid L\left(f_{t}\right), \gamma, \nu\right) / \partial f_{t},
\end{aligned}
$$

where $\nabla_{t}$ is the score of the conditional GHST density with respect to $f_{t}, \omega$ is a vector of fixed intercepts, $A_{i}$ and $B_{j}$ are appropriately sized fixed parameter matrices, $\mathcal{S}_{t}$ is a scaling matrix for the score $\nabla_{t}$, and $\omega=\omega(\theta), A_{i}=A_{i}(\theta)$, and $B_{j}=B_{j}(\theta)$ all depend on a static parameter vector $\theta$. Typical choices for the scaling matrix $\mathcal{S}_{t}$ are $\mathcal{I}_{t-1}^{-a}$ for $a=0,1 / 2,1$, where

$$
\mathcal{I}_{t-1}=\mathrm{E}\left[\nabla_{t} \nabla_{t}^{\prime} \mid y_{t-1}, y_{t-2}, \ldots\right]
$$

is the Fisher information matrix. For exampe, setting $a=1$ sets $\mathcal{S}_{t}=\mathcal{I}_{t-1}^{-1}$ and accounts for the curvature of the score $\nabla_{t}$.

For appropriate choices of the distribution, the parameterization, and the scaling matrix, the GAS model (5)-(6) encompasses a wide range of familiar models, including the (multivariate) GARCH model, the autoregressive conditional duration (ACD) model, and the multiplicative error model (MEM); see Creal, Koopman, and Lucas (2013) for more examples. Details on the parameterization $D_{t}=D\left(f_{t}\right), R_{t}=R\left(f_{t}\right)$, and the scaling matrix $\mathcal{S}_{t}$ used in our empirical application in Section 3 can be found in the appendix. We also show 
in the appendix that

$$
\begin{aligned}
\nabla_{t} & =\Psi_{t}^{\prime} H_{t}^{\prime} \operatorname{vec}\left(w_{t} \cdot y_{t} y_{t}^{\prime}-L_{t} \mathcal{T} \mathcal{T}^{\prime} L_{t}^{\prime}-\left(1-\mu_{\varsigma} w_{t}\right) L_{t} \mathcal{T} \gamma y_{t}^{\prime}\right), \\
w_{t} & =\frac{1}{2}(\nu+n)\left(1-k_{(\nu+n) / 2}^{\prime}\left(\sqrt{d\left(y_{t}\right) \cdot \gamma^{\prime} \gamma}\right) \cdot \sqrt{d\left(y_{t}\right) \cdot \gamma^{\prime} \gamma}\right) / d\left(y_{t}\right),
\end{aligned}
$$

with $k_{a}^{\prime}(b)=\partial \ln K_{a}(b) / \partial b$. The 'weight' function $w_{t}$ decreases in the Mahalanobis distance $d\left(y_{t}\right)$ as defined in (3). The matrices $\Psi_{t}$ and $H_{t}$ are time-varying and parameterization specific and depend on $f_{t}$, but not on the data. The form of the score in equation (7) is very intuitive. Due to the presence of $w_{t}$ in $(7)$, observations that are far out in the tails receive a smaller weight and therefore have a smaller impact on future values of $f_{t}$. This robustness feature is directly linked to the fat-tailed nature of the GHST distribution and allows for smoother correlation and volatility dynamics in the presence of heavy-tailed observations (i.e., $\nu<\infty)$; compare also the robust GARCH literature for an alternative approach, e.g., Boudt, Danielsson, and Laurent (2013).

For skewed distributions $(\gamma \neq 0)$, the score in $(7)$ shows that positive CDS changes have a different impact on correlation and volatility dynamics than negative ones. As explained earlier, this aligns with the intuition that CDS changes from for example the left tail are less informative about changes in volatilities and correlations if the conditional observation density is itself left-skewed. For the symmetric Student's $t$ case, we have $\gamma=0$ and the asymmetry term in (7) drops out. If furthermore the fat-tailedness is ruled out by considering $\nu \rightarrow \infty$, one can show that $w_{t}=\mu_{\varsigma}=1, \mathcal{T}=\mathrm{I}$, and that $\nabla_{t}$ collapses to the intuitive form for a multivariate GARCH model, $\nabla_{t}=\Psi_{t}^{\prime} H_{t}^{\prime} \operatorname{vec}\left(y_{t} y_{t}^{\prime}-\Sigma_{t}\right)$.

Note that the GAS model in (5)-(6) can also be used directly as a dynamic GHST copula model; see McNeil, Frey, and Embrechts (2005) and Patton and Oh (2012, 2013) for the (dynamic) copula approach. In a copula framework, we take $D_{t}=\mathrm{I}$ in the expression $\Sigma_{t}=D_{t} R_{t} D_{t}$, such that only the correlation matrix $R_{t}$ remains to be modeled. As the score of the copula likelihood with respect to the time-varying parameter $f_{t}$ does not depend on 
the marginal distributions, the dynamics as specified in equations (5)-(6) and (7) remain unaltered. The advantage of the copula perspective is that we can allow for more heterogeneity in the marginal distribution of CDS spread changes across countries. We come back to this in the empirical section.

\subsection{Parameter estimation}

The parameters of the dynamic GHST model can be estimated by standard maximum likelihood procedures as the likelihood function is known in closed form using a standard prediction error decomposition. To limit the number of free parameters in the non-linear optimization problem, we use a correlation targeting approach similar to Engle (2002),Hu (2005), and other studies that are based on a multivariate GARCH framework. Let $\omega^{\prime}=\left(\omega_{D}, \omega_{R}\right)$, with $\omega_{D}$ and $\omega_{R}$ denoting the parts of $f_{t}$ describing the dynamics of volatilities $D\left(f_{t}\right)$ and correlations $R\left(f_{t}\right)$, respectively. We then set $\omega_{R}=\tilde{\omega} \cdot\left(\mathrm{I}-B_{1}-\ldots-B_{q}\right)^{-1} \bar{f}_{R}$, where $\bar{f}_{R}$ is such that $R\left(\bar{f}_{R}\right)$ equals the unconditional correlation matrix, and $\tilde{\omega}$ is a scalar parameter that is estimated by maximizing the likelihood.

As an alternative, we also considered a two-step procedure that is commonly found in the literature. In the first step, we estimated univariate models for the volatility dynamics. Using these, we filtered the data. In the second step, we estimated the correlation dynamics based on the filtered data and correlation targeting. The results were qualitatively similar as for the one-step approach sketched above. Moreover, the two-step approach is somewhere half-way the one-step approach and a true copula approach. Therefore, we only report the one-step and copula results in our empirical section. The two-step approach, however, may lead to gains in computational speed with only a modest loss in parameter accuracy for large enough samples. 


\section{Empirical application: euro area sovereign risk}

\subsection{CDS data}

We compute joint and conditional probabilities of a credit event for a set of ten countries in the euro area. We focus on sovereigns that have a CDS contract traded on their reference bonds since the beginning of our sample in January 2008. We select ten countries: Austria (AT), Belgium (BE), Germany (DE), Spain (ES), France (FR), Greece (GR), Ireland (IE), Italy (IT), the Netherlands (NL) and Portugal (PT). CDS spreads are available for these countries at a daily frequency from January 1, 2008 to February 28, 2013, yielding $T=1348$ observations. The CDS contracts have a five year maturity. They are denominated in U.S. dollars, as US dollar denominated contracts are much more liquid than their euro denominated counterparts. The currency issue is complex, as the underlying sovereign bonds are typically denominated in Euros. Moreover, sovereign risk and currency risk may be correlated if investors loose confidence in the Euro after one or more European sovereign defaults. Part of the currency effects may impact CDS prices and cause correlations that are not due to actual clustering of sovereign debt risk. This has to be kept in mind when interpreting the results. All time series data are obtained from Bloomberg.

We prefer CDS spreads to bond yield spreads as a measure of sovereign default risk since the former are less affected by funding liquidity and flight-to-safety issues, see for example Pan and Singleton (2008) and Ang and Longstaff (2011). In addition, our CDS series are likely to be less affected than bond yields by the outright government bond purchases that have taken place during the second half of our sample, see Section 4 below.

Table 1 provides summary statistics for daily de-meaned changes in these ten CDS spreads. All time series have significant non-Gaussian features under standard tests and significance levels. In particular, we note the non-zero skewness and large values of kurtosis for almost all time series in the sample. All series are covariance stationary according to 


\section{Table 1: CDS descriptive statistics}

The summary statistics correspond to daily changes in observed sovereign CDS spreads (in 100 basis points) for ten euro area countries from January 2008 to February 2013. Almost all skewness and excess kurtosis statistics have $p$-values below $10^{-4}$, except the skewness parameters of Germany and Italy.

\begin{tabular}{lrrrrrr}
\hline \hline & Median & Std.Dev. & Skewness & Kurtosis & Minimum & Maximum \\
\hline Austria & 0.00 & 0.05 & 0.65 & 13.26 & -0.27 & 0.42 \\
Belgium & 0.00 & 0.06 & -0.36 & 13.96 & -0.57 & 0.37 \\
Germany & 0.00 & 0.02 & -0.10 & 8.39 & -0.14 & 0.11 \\
Spain & 0.00 & 0.11 & -0.46 & 9.76 & -0.79 & 0.54 \\
France & 0.00 & 0.04 & -0.22 & 10.19 & -0.30 & 0.23 \\
Greece & -0.03 & 4.42 & 2.81 & 60.60 & -43.94 & 56.70 \\
Ireland & 0.00 & 0.16 & -0.95 & 24.42 & -1.79 & 1.19 \\
Italy & 0.00 & 0.11 & 0.09 & 11.30 & -0.77 & 0.72 \\
Netherlands & 0.00 & 0.03 & 0.85 & 11.69 & -0.14 & 0.24 \\
Portugal & 0.00 & 0.23 & -0.55 & 19.68 & -1.92 & 1.75 \\
\hline
\end{tabular}

standard unit root (ADF) tests.

\subsection{Daily model calibration}

We estimate all model parameters over the entire sample. Using the parameter estimates, we compute joint and conditional default probabilities after calibrate the model at each time $t$ to market implied individual probabilities of default as in Segoviano and Goodhart (2009).

The marginal default probabilities are typically estimated directly from observed prices of CDS insurance. We invert a CDS pricing formula to calculate the risk neutral default probabilities following the procedure described in O'Kane (2008). This "bootstrapping" procedure is a standard method in financial practice for marking to market a CDS contract. Since the procedure is standard and available in $\mathrm{O}^{\prime}$ Kane (2008), we only highlight our choices in the implementation. First, we fix the recovery rate at a stressed level of $25 \%$ for all countries. This is roughly in line with the recovery rate that investors received on average in the Greek debt restructuring in Spring 2012, see Zettelmeyer, Trebesch, and Gulati (2012). Second, the term structure of discount rates $r_{t}$ is flat at the one year EURIBOR rate (and 
thus close to zero in our later application). Also, the risk neutral default intensity is assumed to be constant. We note, however, that the precise form of discounting hardly has an effect on our results as the implied risk neutral default intensities are quite robust to the precise form of discounting. Finally, we use a CDS pricing formula that does not take into account counterparty credit risk, see also Huang, Zhou, and Zhu (2009), Black, Correa, Huang, and Zhou (2012), and Creal, Gramacy, and Tsay (2012). Given these choices, a solver quickly finds the (unique) default intensity that matches the expected present values of payments within the premium leg and within the default leg of the CDS. The one year ahead default probability is a simple function of the default intensity; see $\mathrm{O}^{\prime}$ Kane (2008) and Hull and White (2000).

Given the marginal probability of default $p_{i, t}$ of sovereign $i$ at time $t$, we simulate the joint probability of default $p_{i j, t}$ for sovereigns $i$ and $j$ at time $t$ as

$$
p_{i j, t}=\operatorname{Pr}\left[y_{i, t}>F_{i, t}^{-1}\left(p_{i, t}\right), y_{j, t}>F_{j, t}^{-1}\left(p_{j, t}\right)\right],
$$

where $y_{i, t}$ is the $i$ th element of $y_{t}$, and $F_{i, t}^{-1}(\cdot)$ denotes the inverse marginal GHST distribution of sovereign $i$ at time $t$, and where the joint probability of exceedance is computed using the multivariate GHST dependence structure. All marginal and joint GHST probabilities are computed using the model's estimated parameters. The conditional probability for sovereign $j$ defaulting given a default of sovereign $i$ is easily computed as $p_{i j, t} / p_{i, t}$. Note that the joint and conditional default probabilities have a dual time dependence. First, there is dependence on time because the model is re-calibrated to current market conditions $p_{i, t}$ at each time $t$. Second, there is dependence on time because volatilities and correlations vary over time. The second effect impacts both the marginal distributions of $y_{i, t}$ and the joint distribution of $y_{t}$ as specified in Section 2. 


\subsection{Time-varying volatility and correlation}

This section discusses our main empirical results on time-varying volatility and correlation dynamics based on the GHST modeling framework in Section 2. We consider four different choices for the time-varying parameter model specification. The first three correspond to a Gaussian $(\nu=\infty, \gamma=0)$, a Student's $t(\gamma=0)$, and a GHST multivariate distribution, respectively. The fourth approach uses GHST univariate distributions for the marginal distributions, and a GHST copula for the dependence structure. The copula approach is flexible in allowing for heterogeneity across sovereigns in the marginal behavior of CDS spread changes. The computational burden for the dependence part, however, is challenging. This is due to the required numerical inversion of the cumulative distribution function of the GHST for every observation at every evaluation of the likelihood. To facilitate this task, we restrict the number of parameters in the copula by setting $\gamma=\tilde{\gamma}(1, \ldots, 1)^{\prime}$ for some scalar $\tilde{\gamma} \in \mathbb{R}$. Note that we still allow for different skewness parameters for each of the marginal distributions. Also note that the degrees of freedom parameter may be different for each of the marginal distributions, as well as for the marginal distributions and the copula.

In an earlier version of this paper we also considered a GHST model for a fixed degrees of freedom parameter $\nu=5$. The parameter $\nu$ is then treated as a robustness parameter as in Franses and Lucas (1998). The main advantage of fixing $\nu$ is that it increases the computational speed considerably, while most of the qualitative results in terms of the dynamics of joint and conditional default probabilities remain unaltered for the application at hand. We leave the suggestion of using a pre-determined $\nu$ as a robustness device for empirical researchers who are more concerned about computational speed.

There is one important difference between the multivariate GHST and the copula GHST approach that is relevant for the results reported below. The multivariate GHST restricts the degrees of freedom parameter to be the same across all the marginals. As a result, the degrees of freedom parameter determines both the fatness of the marginal tails and the 
degree of tail clustering. Some of the CDS data have very fat tails, pushing the value of $\nu$ downwards. However, as $\nu$ approaches 4 from above, the covariance matrix $\Sigma_{t}$ collapses to a rank one matrix proportional to $\gamma \gamma^{\prime}$, and thus to a perfect correlation case. As this is incompatible with the data, there is an automatic mechanism to push $\nu$ above 4 . The final result balances these two effects. In the copula approach, the step of modeling the marginals versus the dependence structure is split. As a result, the degrees of freedom parameter for the marginal models may become very low, while that for the copula can be substantially higher; see also the empirical results further below. In particular, the degrees of freedom parameters of the marginal models may be below 4 , such that the variance no longer exists. This poses no problem for the computation of joint and conditional default probabilities. It does mean, however, that we can no longer consider a time-varying variance for the marginals. To account for this, we set $\mathcal{T}=1$ for the marginal models in the copula approach and interpret $L_{t}$ as the time-varying scale parameter. The latter is well-defined for any $\nu>0$.

Figure 1 plots the squared CDS spread changes and estimated volatility or scale levels for two countries and four different models. The assumed statistical model (Gaussian, Student- $t$, GHST, Copula) directly influences the dynamics of the volatility estimates. For example, early 2010 the German series spikes for the Gaussian model and then comes down exponentially. For Portugal we see something similar around July 2011. In particular, the temporary increased volatility for the Gaussian series does not appear in line with the subsequent squared CDS spread changes. We see no similar behavior for the GAS models based on fat-tailed distributional assumptions due to the presence of the weighting mechanism $w_{t}$ in $(7)$.

Table 2 reports the parameter estimates of the different models. We estimate all specifications under the restriction of stationarity by reparameterizing $B=(1+\exp (-\tilde{B}))^{-1}$ for $\tilde{B} \in \mathbb{R}$. Standard errors are computed using the likelihood based sandwich covariance ma- 

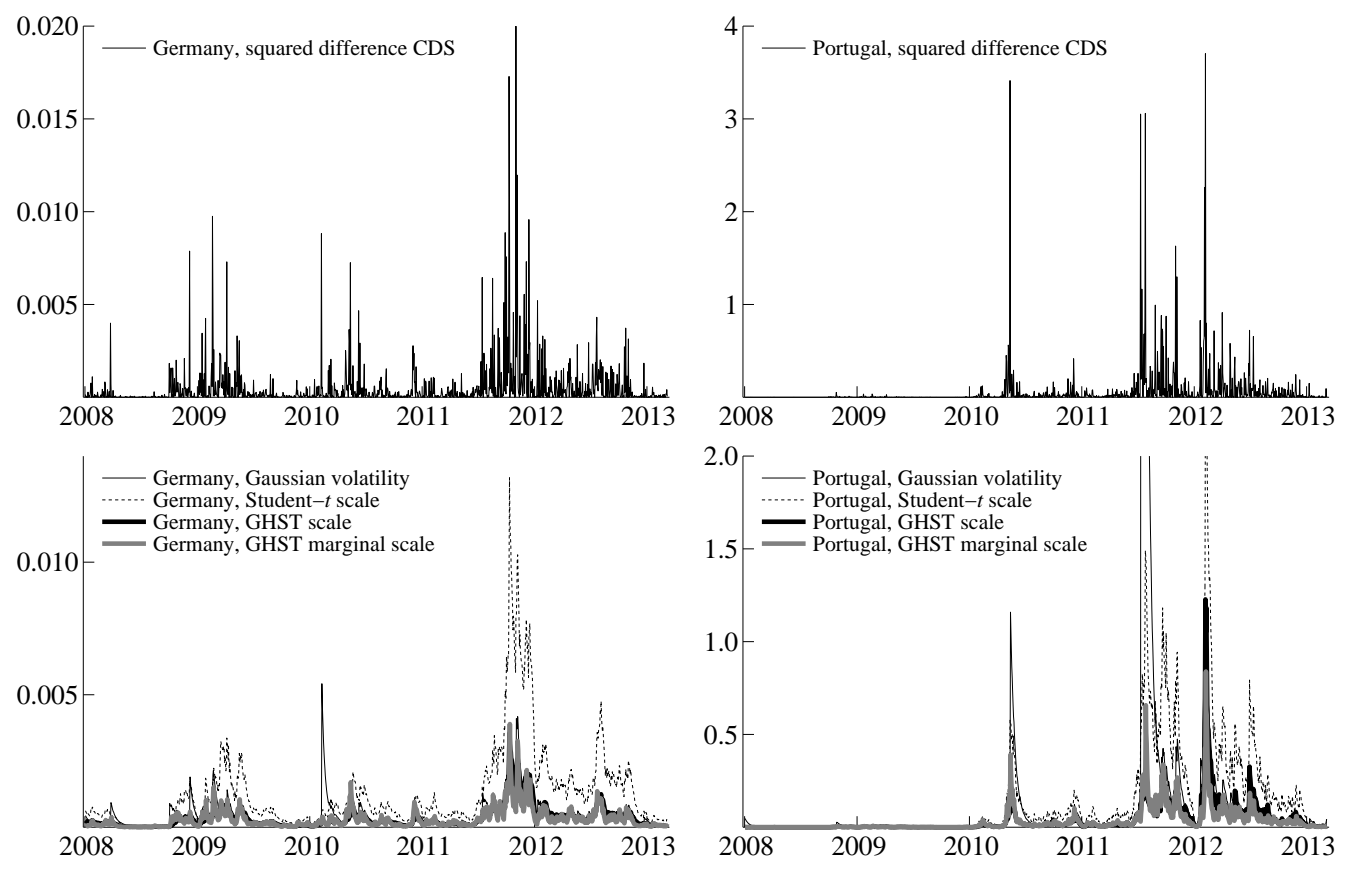

\section{Figure 1: Estimated time varying volatilities for changes in CDS for two countries}

We report four different estimates of time-varying volatility that pertain to changes in CDS spreads on sovereign debt. The estimates are based on different parametric assumptions regarding the univariate distribution of sovereign CDS spread changes: Gaussian, symmetric $t$, and a GHST distribution, and a GHST copula. We pick two countries, Germany and Portugal, to illustrate differences across model specifications. As a direct benchmark, squared CDS spread changes are plotted as well in the top panels. 
trix estimator and the delta method. For all models, volatilities and correlations are highly persistent, i.e., $B$ is numerically equal to or close to one. Note that the parameterization of our score driven model is different than that of a standard GARCH model. In particular, the persistence is completely captured by $B$ rather than by $A+B$ as in the GARCH case. Also note that $\omega$ regularly takes on negative values. This is natural as we define $f_{t}$ to be the log-volatility rather than the volatility itself.

The estimates of the skewness parameters $\gamma$ differ somewhat between the multivariate GHST and the GHST copula specification. For the multivariate GHST, 7 out of the $10 \gamma_{\mathrm{s}}$ are negative, but only those for Greece, Ireland, and Portugal are statistically significant. For the copula, all marginal $\gamma \mathrm{s}$ are positive, but the (common) copula $\gamma$ is negative. The significance of the marginal $\gamma_{\mathrm{s}}$ differs between countries. The copula $\gamma$, however, is highly significant. The difference can be explained by the fact that the multivariate distribution mixes the effect of the marginal distributions with that of the dependence structure. This is no longer the case for the copula. The negative $\gamma$ for the copula increases the sensitivity of the correlation dynamics to common increases in CDS spreads, making sudden common shifts upwards in CDS spreads more likely. The (marginal) volatility dynamics, by contrast, appear less sensitive to large increases in CDS spreads, as follows from the positive $\gamma$ s for the marginal models. The multivariate GHST specification lacks this flexibility.

The degrees of freedom parameter for the Student's $t$ distribution is estimated at $\nu=5.9$. That of the multivariate GHST distribution is estimated even lower at $\nu=4.05$. This is close to the region where the variance no longer exists. As discussed before, the low value of $\nu$ for the GHST mixes the extremely fat-tailed marginal behavior of CDS spread changes for specific countries such as Greece or Ireland, and the multivariate tail dependence structure. The GHST copula approach does not suffer from this automatic link. For the copula specification, we indeed see that 6 countries have a degrees of freedom estimate for the marginal distribution below 4. For the Greek case, the estimate is even close to 2, such 


\section{Table 2: Model parameter estimates}

The table reports parameter estimates that pertain to four different model specifications. The sample consists of daily changes from January 2008 to February 2013. The Student's $t$ and GHST distribution are estimated jointly. The GHST copula is estimated with the same skewness parameter.

\begin{tabular}{|c|c|c|c|c|c|c|c|c|c|c|c|}
\hline & AT & $\mathrm{BE}$ & $\overline{\mathrm{DE}}$ & \multicolumn{7}{|c|}{ Gaussian } & Joint \\
\hline$A$ & $\begin{array}{c}0.058 \\
(0.007)\end{array}$ & $\begin{array}{c}0.070 \\
(0.020)\end{array}$ & $\begin{array}{c}0.075 \\
(0.013)\end{array}$ & $\begin{array}{c}0.066 \\
(0.036)\end{array}$ & $\begin{array}{c}0.085 \\
(0.011)\end{array}$ & $\begin{array}{c}0.096 \\
(0.005)\end{array}$ & $\begin{array}{c}0.073 \\
(0.017)\end{array}$ & $\begin{array}{c}0.092 \\
(0.012)\end{array}$ & $\begin{array}{c}0.082 \\
(0.016)\end{array}$ & $\begin{array}{c}0.089 \\
(0.008)\end{array}$ & $\begin{array}{c}0.015 \\
(0.001)\end{array}$ \\
\hline$B$ & $\begin{array}{c}0.992 \\
(0.003)\end{array}$ & $\begin{array}{c}0.993 \\
(0.010)\end{array}$ & $\begin{array}{c}0.978 \\
(0.011)\end{array}$ & $\begin{array}{c}0.983 \\
(0.022)\end{array}$ & $\begin{array}{c}0.993 \\
(0.007)\end{array}$ & $\begin{array}{c}1.000 \\
(0.000)\end{array}$ & $\begin{array}{c}0.969 \\
(0.010)\end{array}$ & $\begin{array}{c}1.000 \\
(0.000)\end{array}$ & $\begin{array}{c}0.982 \\
(0.010)\end{array}$ & $\begin{array}{c}1.000 \\
(0.000)\end{array}$ & $\begin{array}{c}0.983 \\
(0.002)\end{array}$ \\
\hline$\omega$ & $\begin{array}{l}-3.551 \\
(0.314)\end{array}$ & $\begin{array}{c}-3.684 \\
(0.803)\end{array}$ & $\begin{array}{l}-4.065 \\
(0.150)\end{array}$ & $\begin{array}{l}-2.546 \\
(0.289)\end{array}$ & $\begin{array}{l}-3.952 \\
(0.412)\end{array}$ & $\begin{array}{l}-3.648 \\
(0.294)\end{array}$ & $\begin{array}{l}-2.326 \\
(0.147)\end{array}$ & $\begin{array}{l}-4.211 \\
(0.261)\end{array}$ & $\begin{array}{l}-3.954 \\
(0.196)\end{array}$ & $\begin{array}{c}-3.934 \\
(0.319)\end{array}$ & \\
\hline \multicolumn{12}{|c|}{ Student's $t$} \\
\hline$A$ & $\begin{array}{c}0.127 \\
(0.011)\end{array}$ & $\begin{array}{c}0.126 \\
(0.010)\end{array}$ & $\begin{array}{c}0.110 \\
(0.014)\end{array}$ & $\begin{array}{c}0.136 \\
(0.014)\end{array}$ & $\begin{array}{c}0.138 \\
(0.017)\end{array}$ & $\begin{array}{c}0.148 \\
(0.034)\end{array}$ & $\begin{array}{c}0.150 \\
(0.020)\end{array}$ & $\begin{array}{c}0.138 \\
(0.014)\end{array}$ & $\begin{array}{c}0.125 \\
(0.015)\end{array}$ & $\begin{array}{c}0.184 \\
(0.025)\end{array}$ & $\begin{array}{c}0.022 \\
(0.002)\end{array}$ \\
\hline$B$ & $\begin{array}{c}1.000 \\
(0.000)\end{array}$ & $\begin{array}{c}1.000 \\
(0.000)\end{array}$ & $\begin{array}{c}1.000 \\
(0.000)\end{array}$ & $\begin{array}{c}1.000 \\
(0.001)\end{array}$ & $\begin{array}{c}1.000 \\
(0.000)\end{array}$ & $\begin{array}{c}0.999 \\
(0.001)\end{array}$ & $\begin{array}{c}1.000 \\
(0.000)\end{array}$ & $\begin{array}{c}1.000 \\
(0.000)\end{array}$ & $\begin{array}{c}1.000 \\
(0.000)\end{array}$ & $\begin{array}{c}0.999 \\
(0.001)\end{array}$ & $\begin{array}{c}1.000 \\
(0.000)\end{array}$ \\
\hline$\omega$ & $\begin{array}{l}-3.955 \\
(0.337)\end{array}$ & $\begin{array}{l}-3.405 \\
(0.242)\end{array}$ & $\begin{array}{l}-3.983 \\
(0.281)\end{array}$ & $\begin{array}{l}-3.540 \\
(0.280)\end{array}$ & $\begin{array}{c}-3.504 \\
(0.342)\end{array}$ & $\begin{array}{l}-3.616 \\
(0.279)\end{array}$ & $\begin{array}{l}-3.476 \\
(0.506)\end{array}$ & $\begin{array}{l}-3.436 \\
(0.284)\end{array}$ & $\begin{array}{l}-3.912 \\
(0.296)\end{array}$ & $\begin{array}{l}-3.502 \\
(0.318)\end{array}$ & \\
\hline$\nu$ & & & & & & & & & & & $\begin{array}{c}5.917 \\
(0.210)\end{array}$ \\
\hline \multicolumn{12}{|c|}{ GHST } \\
\hline$A$ & $\begin{array}{c}0.081 \\
(0.008)\end{array}$ & $\begin{array}{c}0.079 \\
(0.007)\end{array}$ & $\begin{array}{c}0.071 \\
(0.011)\end{array}$ & $\begin{array}{c}0.087 \\
(0.010)\end{array}$ & $\begin{array}{c}0.089 \\
(0.011)\end{array}$ & $\begin{array}{c}0.094 \\
(0.025)\end{array}$ & $\begin{array}{c}0.096 \\
(0.013)\end{array}$ & $\begin{array}{c}0.088 \\
(0.009)\end{array}$ & $\begin{array}{c}0.080 \\
(0.011)\end{array}$ & $\begin{array}{c}0.117 \\
(0.016)\end{array}$ & $\begin{array}{c}0.013 \\
(0.001)\end{array}$ \\
\hline$B$ & $\begin{array}{c}0.998 \\
(0.001)\end{array}$ & $\begin{array}{c}0.998 \\
(0.001)\end{array}$ & $\begin{array}{c}0.999 \\
(0.001)\end{array}$ & $\begin{array}{c}0.997 \\
(0.001)\end{array}$ & $\begin{array}{c}0.998 \\
(0.001)\end{array}$ & $\begin{array}{c}0.995 \\
(0.002)\end{array}$ & $\begin{array}{c}0.996 \\
(0.001)\end{array}$ & $\begin{array}{c}0.997 \\
(0.001)\end{array}$ & $\begin{array}{c}0.998 \\
(0.001)\end{array}$ & $\begin{array}{c}0.995 \\
(0.001)\end{array}$ & $\begin{array}{c}1.000 \\
(0.000)\end{array}$ \\
\hline$\omega$ & $\begin{array}{l}-3.787 \\
(0.350)\end{array}$ & $\begin{array}{l}-3.163 \\
(0.255)\end{array}$ & $\begin{array}{l}-3.765 \\
(0.293)\end{array}$ & $\begin{array}{l}-3.343 \\
(0.293)\end{array}$ & $\begin{array}{l}-3.312 \\
(0.349)\end{array}$ & $\begin{array}{l}-2.863 \\
(0.301)\end{array}$ & $\begin{array}{l}-3.288 \\
(0.472)\end{array}$ & $\begin{array}{c}-3.284 \\
(0.290)\end{array}$ & $\begin{array}{l}-3.703 \\
(0.327)\end{array}$ & $\begin{array}{l}-3.342 \\
(0.329)\end{array}$ & \\
\hline$\nu$ & & & & & & & & & & & $\begin{array}{c}4.048 \\
(0.021)\end{array}$ \\
\hline$\gamma$ & $\begin{array}{l}-0.009 \\
(0.021)\end{array}$ & $\begin{array}{l}-0.004 \\
(0.017)\end{array}$ & $\begin{array}{c}0.005 \\
(0.013)\end{array}$ & $\begin{array}{c}-0.023 \\
(0.020)\end{array}$ & $\begin{array}{l}-0.002 \\
(0.014)\end{array}$ & $\begin{array}{c}0.165 \\
(0.036)\end{array}$ & $\begin{array}{l}-0.024 \\
(0.012)\end{array}$ & $\begin{array}{c}0.000 \\
(0.013)\end{array}$ & $\begin{array}{l}-0.008 \\
(0.011)\end{array}$ & $\begin{array}{l}-0.039 \\
(0.016)\end{array}$ & \\
\hline \multicolumn{12}{|c|}{ GHST Copula } \\
\hline$A$ & $\begin{array}{c}0.098 \\
(0.012)\end{array}$ & $\begin{array}{c}0.099 \\
(0.014)\end{array}$ & $\begin{array}{c}0.119 \\
(0.017)\end{array}$ & $\begin{array}{c}0.120 \\
(0.016)\end{array}$ & $\begin{array}{c}0.135 \\
(0.017)\end{array}$ & $\begin{array}{c}0.197 \\
(0.028)\end{array}$ & $\begin{array}{c}0.128 \\
(0.016)\end{array}$ & $\begin{array}{c}0.105 \\
(0.015)\end{array}$ & $\begin{array}{c}0.103 \\
(0.016)\end{array}$ & $\begin{array}{c}0.125 \\
(0.014)\end{array}$ & $\begin{array}{c}0.007 \\
(0.001)\end{array}$ \\
\hline$B$ & $\begin{array}{c}0.993 \\
(0.004)\end{array}$ & $\begin{array}{c}0.991 \\
(0.004)\end{array}$ & $\begin{array}{c}0.974 \\
(0.009)\end{array}$ & $\begin{array}{c}0.989 \\
(0.004)\end{array}$ & $\begin{array}{c}0.985 \\
(0.006)\end{array}$ & $\begin{array}{c}0.985 \\
(0.004)\end{array}$ & $\begin{array}{c}0.990 \\
(0.004)\end{array}$ & $\begin{array}{c}0.991 \\
(0.004)\end{array}$ & $\begin{array}{c}0.983 \\
(0.007)\end{array}$ & $\begin{array}{c}0.991 \\
(0.003)\end{array}$ & $\begin{array}{c}0.993 \\
(0.001)\end{array}$ \\
\hline$\omega$ & $\begin{array}{l}-3.530 \\
(0.457)\end{array}$ & $\begin{array}{l}-3.422 \\
(0.347)\end{array}$ & $\begin{array}{l}-4.305 \\
(0.159)\end{array}$ & $\begin{array}{l}-2.689 \\
(0.345)\end{array}$ & $\begin{array}{c}-3.843 \\
(0.294)\end{array}$ & $\begin{array}{l}-1.330 \\
(0.362)\end{array}$ & $\begin{array}{l}-2.572 \\
(0.402)\end{array}$ & $\begin{array}{l}-2.736 \\
(0.385)\end{array}$ & $\begin{array}{l}-4.172 \\
(0.199)\end{array}$ & $\begin{array}{l}-2.219 \\
(0.439)\end{array}$ & \\
\hline$\nu$ & $\begin{array}{c}3.742 \\
(0.419)\end{array}$ & $\begin{array}{c}4.115 \\
(0.487)\end{array}$ & $\begin{array}{c}4.452 \\
(0.567)\end{array}$ & $\begin{array}{c}3.989 \\
(0.436)\end{array}$ & $\begin{array}{c}4.316 \\
(0.552)\end{array}$ & $\begin{array}{c}2.074 \\
(0.070)\end{array}$ & $\begin{array}{c}3.028 \\
(0.279)\end{array}$ & $\begin{array}{c}3.894 \\
(0.460)\end{array}$ & $\begin{array}{c}3.638 \\
(0.454)\end{array}$ & $\begin{array}{c}4.590 \\
(0.619)\end{array}$ & $\begin{array}{c}10.291 \\
(1.049)\end{array}$ \\
\hline$\gamma$ & $\begin{array}{c}0.077 \\
(0.029)\end{array}$ & $\begin{array}{c}0.090 \\
(0.035)\end{array}$ & $\begin{array}{c}0.056 \\
(0.034)\end{array}$ & $\begin{array}{c}0.056 \\
(0.028)\end{array}$ & $\begin{array}{c}0.085 \\
(0.035)\end{array}$ & $\begin{array}{c}0.013 \\
(0.012)\end{array}$ & $\begin{array}{c}0.020 \\
(0.016)\end{array}$ & $\begin{array}{c}0.070 \\
(0.030)\end{array}$ & $\begin{array}{c}0.059 \\
(0.029)\end{array}$ & $\begin{array}{c}0.119 \\
(0.041)\end{array}$ & $\begin{array}{l}-0.008 \\
(0.001)\end{array}$ \\
\hline
\end{tabular}


that the mean may no longer exist. By contrast, the degrees of freedom parameter for the dependence structure is estimated at $\nu=10.3$, such that tail dependence for the copula specification is smaller. How the different effects balance out when computing the joint and conditional default probabilities is shown in the next subsections.

Figure 2 plots the average correlation, averaged across 45 bivariate time varying pairs, for each model specification. The dynamic correlation coefficients refer to the standardized CDS spread changes. Given $n=10$, there are $n(n-1) / 2=45$ different elements in the correlation matrix. As a robustness check, we benchmark each multivariate model-based estimate to the average over 45 correlation pairs obtained from a 60 business days rolling window. Over each window we use the same pre-filtered marginal data as for the multivariate model estimates. Comparing the correlation estimates across different specifications, the GHST model matches the rolling window estimates most closely.

Correlations increased visibly during times of stress. GHST correlations are low in the beginning of the sample at around 0.3 and increase to around 0.75 during 2010 and 2011 . Estimated dependence across euro area sovereign risk increases sharply for the first time around September 15, 2008, on the day of the Lehman bankruptcy, and around September 30, 2008, when the Irish government issued a broad guarantee for the deposits and borrowings of six large financial institutions. Average GHST correlations remain high afterwards, around 0.75, until around May 10, 2010. At this time, euro area heads of state introduced a rescue package that contained government bond purchases by the ECB under the so-called Securities Markets Program, and the European Financial Stability Facility, a fund designed to provide financial assistance to euro area states in economic difficulties. After an eventual decline to around 0.5 towards the beginning of 2013 .

\subsection{Joint sovereign risk during the euro area debt crisis}

This section discusses the probability of the extreme (tail) possibility that two or more credit events take place in our sample of ten euro area countries, over a one year horizon, 

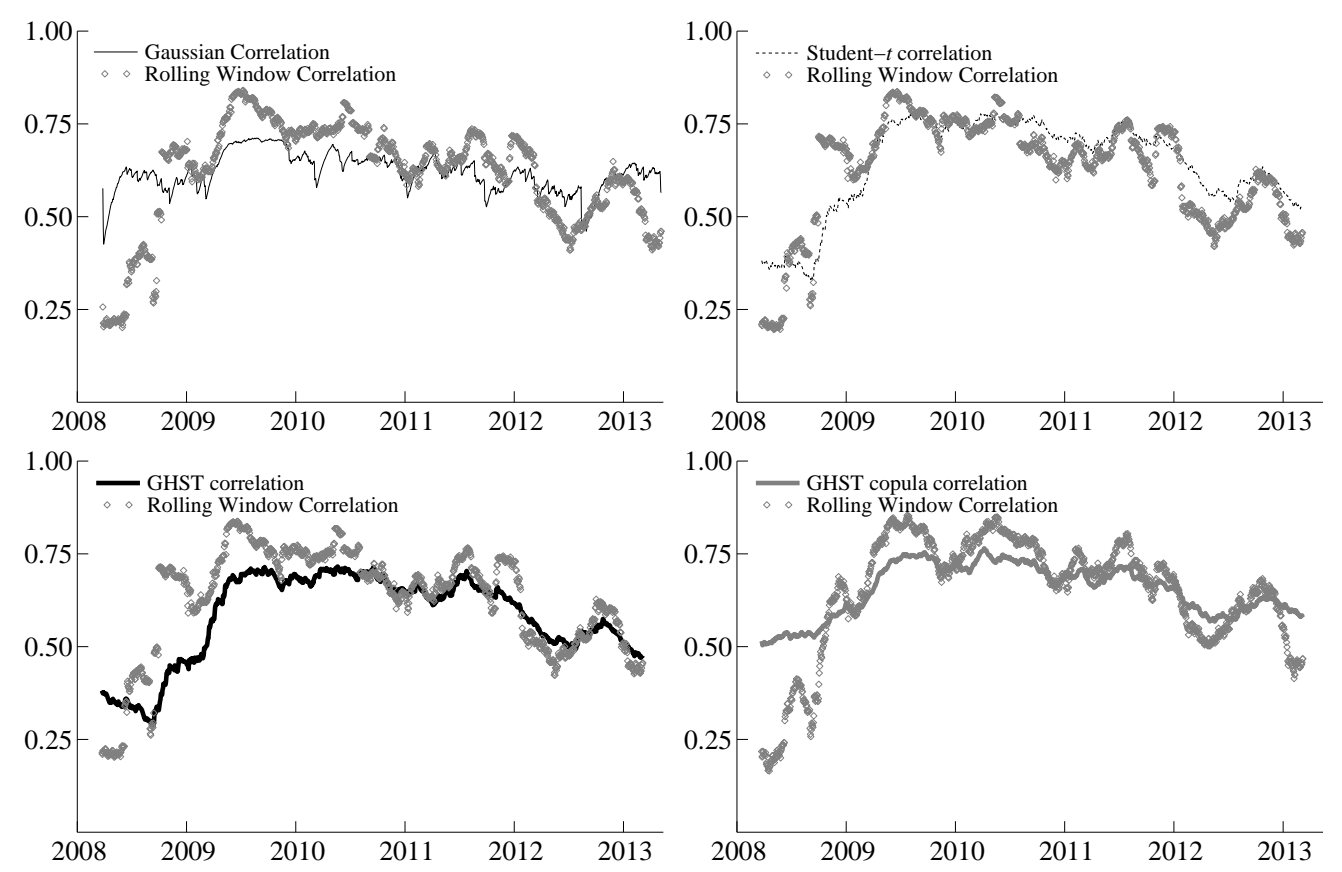

Figure 2: Average correlation over time

Plots of the estimated average correlation over time, where averaging takes place over 45 estimated correlation coefficients. The correlations are estimated based on different parametric assumptions: Gaussian, symmetric $t$, and GH Skewed- $t$ (GHST), and GHST copula. The time axis runs from March 2008 to February 2013. The corresponding rolling window correlations are each estimated using a window of sixty business days of pre-filtered CDS changes. 


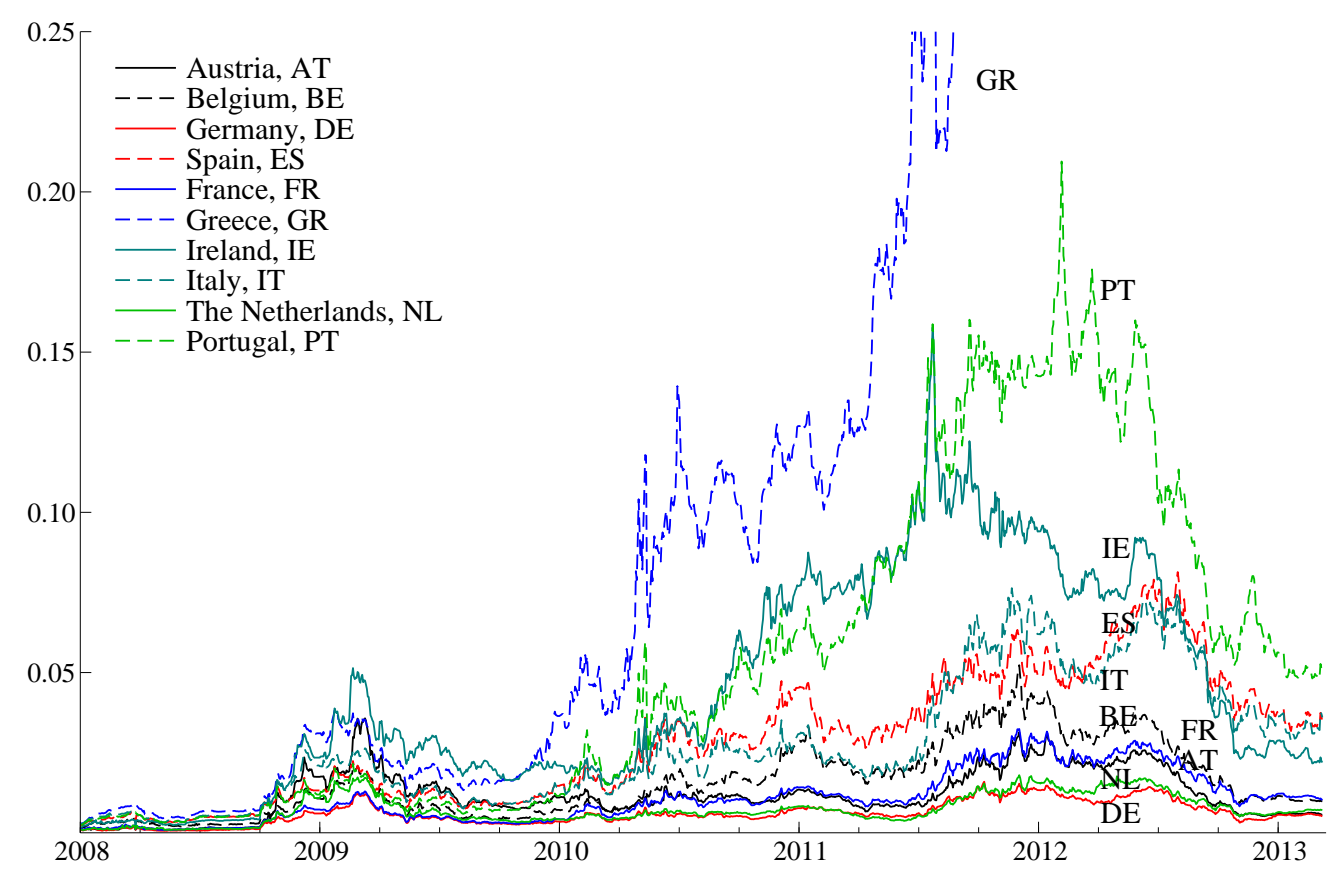

Figure 3: CDS-implied marginal probabilities of a credit event

The risk neutral marginal probabilities of a credit event for ten euro area countries are extracted from CDS prices. The sample is daily data from 01 January 2008 to 28 February 2013.

as perceived by credit market participants. Such a probability depends on the perceived country-specific (marginal) probabilities, as well as the dependence structure.

Figure 3 plots estimates of marginal CDS-implied probabilities of default (pd) over a one year horizon obtained as described in Section 3.2 and in for example Segoviano and Goodhart (2009). These probabilities are directly inferred from CDS spreads and do not depend on parametric assumptions regarding their joint distribution. Market-implied pds vary markedly in the cross section, ranging from below $2 \%$ for some countries to above $8 \%$ for Greece, Portugal, and Ireland during the second half of 2011. The market-implied probability of a credit event in Greece leaves the chart in mid-2011 (>25\%).

Figure 4 plots the market-implied probability of two or more credit events among ten euro area countries over a one year horizon. The joint probability is calculated by simulation, using 50,000 draws at each time $t$. For each simulation, we keep track of the joint exceedance 


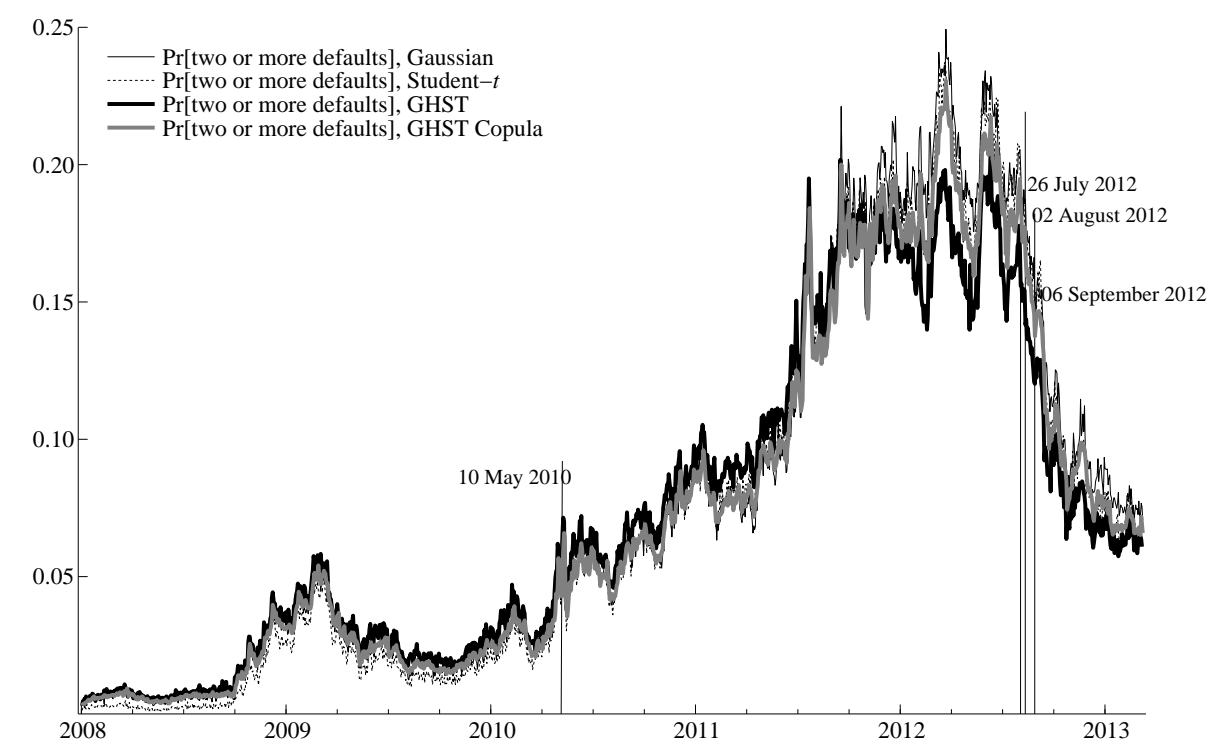

Figure 4: Probability of two or more credit events

The top panel plots the time-varying probability of two or more credit events (out of ten) over a oneyear horizon. Estimates are based on different distributional assumptions regarding marginal risks and multivariate dependence: Gaussian, symmetric- $t$, and GH skewed- $t$ (GHST) distribution, and a GHST copula with GHST marginals. Vertical lines refer to program announcements on the 10 May 2010 (SMP and EFSF), and on the 02 August 2012 (OMT) and 06 September 2012 (details on OMT); see Section 4.

of $y_{i, t}$ and $y_{j, t}$ above their calibrated thresholds at time $t$, as described in Section 3.2. This simple estimate combines all marginal risk estimates and 45 correlation parameter estimates into a single time series plot. The plot reflects, first, the deterioration of debt conditions since the beginning of the debt crisis in Spring 2010, and second, a clear turning of the tide around mid-2012. Vertical lines indicate the announcement of a first euro area rescue package (the EFSF and SMP) on 10 May 2010, and announcements regarding the Outright Monetary Transactions (OMT) in August and September 2012, which we revisit in Section 4 below.

There are only slightly different patterns in the estimated probabilities of joint default in Figure 4; the overall dynamics are roughly similar across the different distributional specifications. In the beginning of our sample, the joint default probability from the GHST multivariate distribution somewhat higher than that from the Gaussian, symmetric-t, and 
GHST copula models. This pattern reverses in mid-2011, when the Gaussian, symmetric- $t$, and GHST copula estimates are slightly higher than the GHST multivariate density estimate. Altogether, the level and dynamics in the estimated measures of joint default from this section do not appear to be very sensitive to the precise model specification.

\subsection{Conditional risk and risk spillovers}

This section investigates conditional probabilities of default. Such conditional probabilities relate to questions of "what if?". In addition, a cross-sectional comparison may help reveal which entities are expected by credit markets to be relatively more affected by a certain credit event. To our knowledge, this is the first attempt in the literature to evaluate such market perceptions. Clearly, conditioning on a credit event is different from conditioning on incremental changes in risk, see Caceres, Guzzo, and Segoviano (2010) and Caporin, Pelizzon, Ravazzolo, and Rigobon (2012b).

We condition on a credit event in Greece to illustrate our general methodology. We pick this event since it has by far the highest market-implied probability of occurring during most of our sample period, and indeed occurred on 08 March 2012. Figure 5 plots the conditional probability of a credit event, as perceived by credit markets, for nine euro area countries. We again consider the four parametric multivariate models considered in the previous sections.

We document three empirical findings. First, during 2011 Ireland and Portugal are perceived by credit market participants to be more affected by a possible Greek default than the other countries, with conditional probabilities around $30 \%$; this is similar for all fat-tailed parametric specifications. The conditional probability estimates for the Gaussian model are lower at a level slightly above 20\%. Ireland and Portugal were in an EU-IMF program during 2011. The other seven countries appear more 'ring-fenced' during that time, with conditional probabilities below 20\%. As a result, credit market participants appear to be most concerned about the adverse fallout for countries that are already in a fiscally weaker position. This is intuitive, for example because sovereign fiscal backstops for the 
financial sector are less strong.

Second, the level and dynamics of the conditional estimates are clearly sensitive to the parametric assumptions. The conditional probability estimates are highest in the GHST density and copula case, with the symmetric-t estimates second, and the Gaussian case last. The correlations and the mixing variable $\varsigma_{t}$ in equation (1) thus operate together to capture the tail dependence in the data. Accounting for this tail dependence changes the conditional risk assessments.

Finally, and interestingly, the conditional probabilities decrease markedly since the second half of 2011. This is a time when the CDS-implied marginal probability of a Greek credit event increases from about $25 \%$ to close to one (>90\% in December 2011). As the eventual default becomes more and more likely, and is eventually almost entirely priced into CDS contracts and sovereign bonds, also the perceived fallout for the other countries in our sample is reduced. This is consistent with the notion that market participants prepare for the contingency of a default as it becomes more and more apparent. When the credit event actually happened, it was widely anticipated and markets were relatively unfazed; see Reuters (2012).

\section{Event study: asset purchase announcements and sovereign risk dependence}

This section investigates the immediate impact of two key policy announcements on sovereign risk conditions as perceived by credit market participants. We document that each policy announcement had a very strong effect on joint sovereign risk perceptions, cutting some perceived joint risks by up to $50 \%$. We show that this pronounced impact worked through decreasing marginal risks, and not by lowering risk dependence. For all analyses in this section, we use the GHST copula specification of the model as it is the most flexible specification.

During a weekend meeting on May 8-9, 2010, euro area heads of state agreed on a com- 

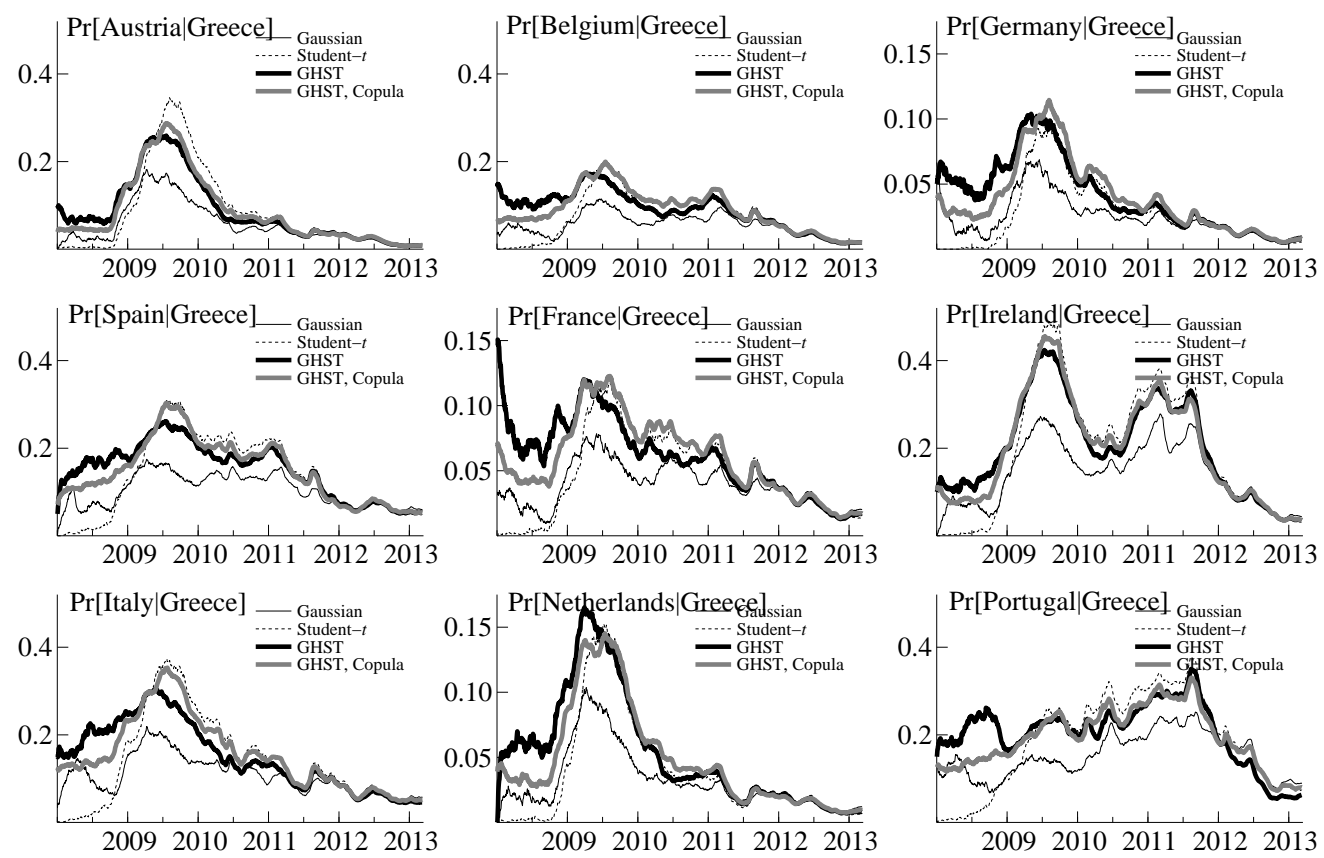

Figure 5: Conditional probabilities of a credit event given a Greek credit event Plots of annual conditional probabilities of a credit event for nine countries in the euro area given a credit event in Greece. We distinguish conditional risk estimates based on a Gaussian dependence structure, symmetric- $t$, GH skewed- $t$ (GHST) multivariate density, and a GHST copula with GHST marginals. 
prehensive rescue package to mitigate sovereign risk conditions and potential risk contagion in the Eurozone. The rescue package contained two main measures: the European Financial Stability Facility (EFSF) and the ECB's Securities Markets Program (SMP). The EFSF is a limited liability facility with an objective to preserve financial stability of the euro area by providing temporary financial assistance to euro area member states in economic difficulties. Initially committed funds were 440bn Euro. The announcement made clear that EFSF funds could be combined with funds raised by the European Commission of up to 60bn Euro, and funds from the International Monetary Fund of up to 250bn Euro, for a total safety net up to 750 bn Euro. The other key component of the rescue package was a government bond buying program, the SMP. Specifically, the ECB announced that it would start to intervene in secondary government bond markets to ensure depth and liquidity in those market segments that are qualified as being dysfunctional. These purchases were meant to restore an appropriate monetary policy transmission mechanism, see ECB (2010). The joint announcement impacted asset prices on Monday 10 May 2010.

The impact of the 10 May 2010 announcement on joint sovereign risk perceptions (as well as that of the initial bond purchases) is visible in Figure 4. The figure suggests that the probability of two or more credit events in our sample of ten countries decreases from about $7 \%$ to approximately $3 \%$ before and after the announcement, thus virtually overnight. Figure 3 indicates that marginal risks decreased considerably as well. The average correlation plots in Figure 2 do not suggest a wide-spread and prolonged decrease in dependence. Instead, there seems to be an up-tick in average correlations.

To further investigate the impact on joint and conditional sovereign risk from actions communicated on 10 May 2010 and implemented shortly afterwards, Table 3 reports modelbased estimates of joint and conditional risk. We report our risk estimates for two dates, Thursday May 6, 2010 and Tuesday May 11, 2011, i.e., two business days before and after the announced change in policy. The top panel of Table 3 confirms that the joint probability 
of a credit event in, say, both Portugal and Greece, or Ireland and Greece, declines from 3.8\% to $1.7 \%$ and from $2.5 \%$ to $1.3 \%$, respectively. These are large declines in joint risk, cutting some perceived risks in half. For any country in the sample, the probability of that country failing simultaneously with Greece or Portugal over a one year horizon is substantially lower after the 10 May 2010 announcement than before. The bottom panel of Table 3 indicates that the decrease in joint default probabilities is generally not due to a decline in default dependence. Instead, the perceived conditional probabilities of a credit event in for example Greece or Ireland given a credit event in Portugal remains roughly constant from $63 \%$ to $59 \%$ and from $38 \%$ to $38 \%$, respectively. Similarly, the perceived conditional probabilities of a credit event in Belgium or Ireland given a credit event in Greece only move from $9 \%$ to $11 \%$ and from $21 \%$ to $19 \%$, respectively.

Figures 4 and 3 also suggest that the impact of the 10 May 2010 announcement was temporary. Sovereign yields soon started to rise afterwards in some euro area countries. Figure 4 would suggest that the height of the euro area debt crisis could be dated from mid-2011 to mid-2012.

A visible break of the upward trend in joint risk can be associated with three dates in 2012 (also visible as vertical lines in Figure 4). On 26 July 2012, the president of the ECB pledged to do "whatever it takes" to preserve the euro, and that "it will be enough". In the speech, sovereign risk premia were mentioned as a key concern within the ECB's mandate, see Draghi (2012). Communication regarding a new asset purchase program, the Outright Monetary Transactions (OMT), followed swiftly afterwards on 2nd August. The OMT is an asset purchase program that replaces the earlier SMP, see ECB (2012) for details. These details on OMT were communicated on 06 September 2012. The joint impact of the three measures on joint risk in clearly visible in Figure 4. For a discussion of this figure in the context of central bank communication in the financial press, see Wessel (2013).

Table 3 reports model-based estimates of joint and conditional risk around the OMT 


\section{Table 3: Sovereign risk perceptions around SMP and EFSF announcement}

The top and bottom panels report GHST copula model-implied joint and conditional probabilities of a credit event for a subset of countries, respectively. For the conditional probabilities $\operatorname{Pr}(i$ defaulting $\mid j$ defaulted $)$, the conditioning events $j$ are in the columns (PT, GR, ES), while the events $i$ are in the rows (AT, BE, ... PT). Avg contains the averages for each column. Joint and conditional risks are reported two business days before and after the 10 May 2010 announcement.

\begin{tabular}{lccr|rrr}
\hline \multicolumn{7}{c}{ Joint risk, $\operatorname{Pr}(\mathrm{i} \cap \mathrm{j})$} \\
\hline & Thu & May 2010 & \multicolumn{3}{c}{ Tue 11 May 2010} \\
& PT & GR & ES & PT & GR & ES \\
\hline AT & $0.9 \%$ & $0.9 \%$ & $0.8 \%$ & $0.5 \%$ & $0.6 \%$ & $0.4 \%$ \\
BE & $1.1 \%$ & $1.1 \%$ & $0.9 \%$ & $0.7 \%$ & $0.7 \%$ & $0.5 \%$ \\
DE & $0.6 \%$ & $0.7 \%$ & $0.6 \%$ & $0.4 \%$ & $0.4 \%$ & $0.3 \%$ \\
ES & $2.5 \%$ & $2.5 \%$ & & $1.2 \%$ & $1.2 \%$ & \\
FR & $0.9 \%$ & $0.9 \%$ & $0.8 \%$ & $0.5 \%$ & $0.6 \%$ & $0.4 \%$ \\
GR & $3.8 \%$ & & $2.5 \%$ & $1.7 \%$ & & $1.2 \%$ \\
IE & $2.3 \%$ & $2.5 \%$ & $1.8 \%$ & $1.1 \%$ & $1.3 \%$ & $0.9 \%$ \\
IT & $2.1 \%$ & $2.2 \%$ & $1.8 \%$ & $1.1 \%$ & $1.2 \%$ & $1.0 \%$ \\
NL & $0.5 \%$ & $0.5 \%$ & $0.4 \%$ & $0.3 \%$ & $0.3 \%$ & $0.3 \%$ \\
PT & & $3.8 \%$ & $2.5 \%$ & & $1.7 \%$ & $1.2 \%$ \\
\hline Avg & $1.6 \%$ & $1.7 \%$ & $1.3 \%$ & $0.8 \%$ & $0.9 \%$ & $0.7 \%$ \\
\hline
\end{tabular}

\begin{tabular}{|c|c|c|c|c|c|c|}
\hline \multicolumn{7}{|c|}{ Conditional risk, $\operatorname{Pr}(\mathrm{i} \mid \mathrm{j})$} \\
\hline & \multicolumn{3}{|c|}{ Thu 06 May 2010} & \multicolumn{3}{|c|}{ Tue 11 May 2010} \\
\hline & $\mathrm{PT}$ & GR & ES & $\mathrm{PT}$ & GR & ES \\
\hline AT & $15 \%$ & $8 \%$ & $21 \%$ & $17 \%$ & $8 \%$ & $20 \%$ \\
\hline $\mathrm{BE}$ & $18 \%$ & $9 \%$ & $24 \%$ & $24 \%$ & $11 \%$ & $26 \%$ \\
\hline $\mathrm{DE}$ & $11 \%$ & $6 \%$ & $16 \%$ & $13 \%$ & $6 \%$ & $15 \%$ \\
\hline ES & $42 \%$ & $22 \%$ & & $42 \%$ & $18 \%$ & \\
\hline FR & $14 \%$ & $8 \%$ & $21 \%$ & $18 \%$ & $8 \%$ & $21 \%$ \\
\hline GR & $63 \%$ & & $70 \%$ & $59 \%$ & & $58 \%$ \\
\hline IE & $38 \%$ & $21 \%$ & $50 \%$ & $38 \%$ & $19 \%$ & $45 \%$ \\
\hline IT & $35 \%$ & $18 \%$ & $50 \%$ & $37 \%$ & $17 \%$ & $48 \%$ \\
\hline NL & $8 \%$ & $4 \%$ & $11 \%$ & $11 \%$ & $5 \%$ & $12 \%$ \\
\hline PT & & $32 \%$ & $69 \%$ & & $26 \%$ & $58 \%$ \\
\hline Avg & $27 \%$ & $14 \%$ & $37 \%$ & $29 \%$ & $13 \%$ & $34 \%$ \\
\hline
\end{tabular}


Table 4: Sovereign risk perceptions around OMT announcements

The top and bottom panels report GHST copula model-implied joint and conditional probabilities of a credit event for a subset of countries, respectively. For the conditional probabilities $\operatorname{Pr}(i$ defaulting $\mid j$ defaulted $)$, the conditioning events $j$ are in the columns (PT, GR, ES), while the events $i$ are in the rows (AT, BE, ... PT). Avg contains the averages for each column. Joint and conditional risks are reported two business days before the 26 July 2012 and after the 06 September 2012 announcement of the OMT details.

\begin{tabular}{lrrr|rrr}
\hline \multicolumn{7}{c}{ Joint risk, $\operatorname{Pr}(\mathrm{i} \cap \mathrm{j})$} \\
\hline & Tue 24 Jul 2012 & \multicolumn{3}{c}{ Fri 07 Sep 2012 } \\
& PT & GR & ES & PT & GR & ES \\
\hline AT & $1.0 \%$ & $1.7 \%$ & $1.2 \%$ & $0.5 \%$ & $0.8 \%$ & $0.7 \%$ \\
BE & $1.5 \%$ & $2.6 \%$ & $1.8 \%$ & $0.9 \%$ & $1.6 \%$ & $1.3 \%$ \\
DE & $0.6 \%$ & $1.0 \%$ & $0.7 \%$ & $0.3 \%$ & $0.6 \%$ & $0.5 \%$ \\
ES & $3.3 \%$ & $7.7 \%$ & & $1.9 \%$ & $4.1 \%$ & \\
FR & $1.2 \%$ & $2.3 \%$ & $1.5 \%$ & $0.8 \%$ & $1.4 \%$ & $1.1 \%$ \\
GR & $10.7 \%$ & & $7.7 \%$ & $5.8 \%$ & & $4.1 \%$ \\
IE & $3.9 \%$ & $7.1 \%$ & $3.4 \%$ & $2.1 \%$ & $4.1 \%$ & $2.3 \%$ \\
IT & $3.2 \%$ & $6.8 \%$ & $4.7 \%$ & $1.9 \%$ & $3.9 \%$ & $2.9 \%$ \\
NL & $0.7 \%$ & $1.2 \%$ & $0.8 \%$ & $0.4 \%$ & $0.8 \%$ & $0.6 \%$ \\
PT & & $10.7 \%$ & $3.3 \%$ & & $5.8 \%$ & $1.9 \%$ \\
\hline Avg & $2.9 \%$ & $4.6 \%$ & $2.8 \%$ & $1.6 \%$ & $2.6 \%$ & $1.7 \%$ \\
\hline
\end{tabular}

\begin{tabular}{|c|c|c|c|c|c|c|}
\hline \multicolumn{7}{|c|}{ Conditional risk, $\operatorname{Pr}(\mathrm{i} \mid \mathrm{j})$} \\
\hline & \multicolumn{3}{|c|}{ Tue 24 Jul 2012} & \multicolumn{3}{|c|}{ Fri 07 Sep 2012} \\
\hline & $\mathrm{PT}$ & GR & ES & $\mathrm{PT}$ & GR & ES \\
\hline AT & $9 \%$ & $2 \%$ & $14 \%$ & $8 \%$ & $1 \%$ & $16 \%$ \\
\hline $\mathrm{BE}$ & $13 \%$ & $3 \%$ & $23 \%$ & $13 \%$ & $2 \%$ & $30 \%$ \\
\hline $\mathrm{DE}$ & $5 \%$ & $1 \%$ & $8 \%$ & $5 \%$ & $1 \%$ & $11 \%$ \\
\hline $\mathrm{ES}$ & $29 \%$ & $8 \%$ & & $29 \%$ & $5 \%$ & \\
\hline FR & $11 \%$ & $2 \%$ & $19 \%$ & $12 \%$ & $2 \%$ & $25 \%$ \\
\hline GR & $95 \%$ & & $96 \%$ & $88 \%$ & & $92 \%$ \\
\hline IE & $34 \%$ & $8 \%$ & $43 \%$ & $32 \%$ & $5 \%$ & $51 \%$ \\
\hline $\mathrm{IT}$ & $28 \%$ & $7 \%$ & $59 \%$ & $28 \%$ & $5 \%$ & $65 \%$ \\
\hline NL & $6 \%$ & $1 \%$ & $10 \%$ & $7 \%$ & $1 \%$ & $13 \%$ \\
\hline $\mathrm{PT}$ & & $12 \%$ & $41 \%$ & & $7 \%$ & $42 \%$ \\
\hline Avg & $26 \%$ & $5 \%$ & $35 \%$ & $25 \%$ & $3 \%$ & $28 \%$ \\
\hline
\end{tabular}


announcements. We compare risk estimates for Tuesday, 24 July 2012 (two days before the speech) to risk estimates for Friday, 07 September 2012 (two days after the announcement of the OMT details). A common finding emerges. Just as in the case of the 10 May 2010 announcement, joint risks have decreased markedly. For example, the joint probability of a credit event in both Spain and Italy over a one year horizon decreased from $4.7 \%$ to $2.9 \%$. Similar reductions are observed for other countries as well. Second, the decrease in joint risk is generally not due to a decline in dependence, or perceived connectedness. Instead, the conditional probabilities of a credit event remain very similar, despite the period of more than two months between the two measurement dates. This suggests that market perceptions regarding risk interactions remained a concern.

We conclude that both the 10 May 2010 and 2012 policy announcements had a very strong effect on joint sovereign risk perceptions, cutting some perceived joint risks by up to 50\%. This pronounced impact worked through decreasing marginal risks, not perceived risk dependence. These findings are robust to alternative statistical choices (such as the degrees of freedom in the dependence model), as well as to alternative ways of extracting marginal risks from CDS prices (such as recovery rates assumptions in the case of a credit event).

\section{Conclusion}

We have proposed a novel empirical framework to assess risk perceptions regarding joint and conditional default based on the price of CDS insurance. Our methodology is novel in that our joint risk measures are derived from a multivariate framework based on a dynamic Generalized Hyperbolic skewed- $t$ conditional density that naturally accommodates skewed and heavy-tailed changes in marginal risks as well as time variation in volatility and multivariate dependence. When applying the model to euro area sovereign CDS data from January 2008 to February 2013, we find significant time variation in risk dependence, evidence for risk spillovers regarding sovereign credit events, as well as a strong impact of key policy 
announcements during the euro area debt crisis on joint and conditional sovereign risk perceptions. Regarding model risk, parametric assumptions, in particular assumptions about higher order moments and their dynamics, matter for joint and conditional risk assessments.

\section{References}

Aas, K. and I. Haff (2006). The generalized hyperbolic skew student's $t$ distribution. Journal of Financial Econometrics 4(2), 275-309.

Abramowitz, M. and I. A. Stegun (1970). Handbook of Mathematical Function with Formulas, Graphs, and Mathematical Tables. National Bureau of Standsards, Applied Mathematics Series, Vol. 55.

Acharya, V. V., L. H. Pedersen, T. Philippon, and M. Richardson (2010). Measuring systemic risk. NYU working paper.

Ang, A. and F. Longstaff (2011). Systemic sovereign credit risk: Lessons from the US and Europe. NBER discussion paper 16983.

Avesani, R. G., A. G. Pascual, and J. Li (2006). A new risk indicator and stress testing tool: A multifactor nth-to-default cds basket. IMF Working Paper, WP/06/105.

Azzalini, A. and A. Capitanio (2003). Distributions generated by perturbation of symmetry with emphasis on a multivariate skew $t$ distribution. Journal ofthe Royal Statistical Society B 65, 367-389.

Bauwens, L. and S. Laurent (2005). A new class of multivariate skew densities, with application to generalized autoregressive conditional heteroskedasticity models. Journal of Business and Economic Statistics 23(3), 346-354.

Benzoni, L., P. Collin-Dufresne, R. Goldstein, and J. Helwege (2011). Modeling credit contagion via the updating of fragile beliefs. mimeo. 
Black, L., R. Correa, X. Huang, and H. Zhou (2012). The systemic risk of European banks during the financial and sovereign debt crisis. mimeo.

Boudt, K., J. Danielsson, and S. Laurent (2013). Robust forecasting of dynamic conditional correlation GARCH models. International Journal of Forecasting, forthcoming.

Branco, M. and D. Dey (2001). A general class of multivariate skew-elliptical distributions. Journal of Multivariate Analysis 79, 99-113.

Caceres, C., V. Guzzo, and M. Segoviano (2010). Sovereign Spreads: Global Risk Aversion, Contagion or Fundamentals? IMF working paper WP/10/120.

Caporin, M., L. Pelizzon, F. Ravazzolo, and R. Rigobon (2012a). Measuring sovereign contagion in Europe. mimeo.

Caporin, M., L. Pelizzon, F. Ravazzolo, and R. Rigobon (2012b). Measuring sovereign contagion in Europe. mimeo.

Chen, Y., W. Härdle, and V. Spokoiny (2010). GHICA — Risk analysis with GH distributions and independent components. Journal of Empirical Finance 17(2), 255-269.

Christoffersen, P., V. Errunza, K. Jacobs, and H. Langlois (2011). Is the Potential for International Diversification Disappearing? working paper.

Creal, D., S. J. Koopman, and A. Lucas (2011). A dynamic multivariate heavy-tailed model for time-varying volatilities and correlations. Journal of Economic and Business Statistics 29(4), 552-563.

Creal, D., S. J. Koopman, and A. Lucas (2013). Generalized Autoregressive Score Models with Applications. Journal of Applied Econometrics, forthcoming.

Creal, D. D., R. B. Gramacy, and R. S. Tsay (2012). Market-based credit ratings. working paper.

DeGrauwe, P. and Y. Ji (2012). Mispricing of sovereign risk and multiple equilibria in the Eurozone. working paper. 
Demarta, S. and A. J. McNeil (2005). The t copula and related copulas. International Statistical Review 73, 111-129.

Doornik, J. A. (2007). Ox: An Object-Oriented Matrix Language. Timberlake Consultants Press, London.

Draghi, M. (2012). Speech at the global investment conference in london. July 26.

ECB (2010). Ecb decides on measures to address severe tensions in financial markets. ECB press release, May 10.

ECB (2012). Technical features of outright monetary transactions. ECB press release, September 6 .

Engle, R. (2002). Dynamic conditional correlation. Journal of Business and Economic Statistics 20(3), 339-350.

Engle, R. F. and B. T. Kelly (2012). Dynamic Equicorrelation. Journal of Business and Economic Statistics 30(2), 212-228.

Forbes, K. and R. Rigobon (2002). No contagion, only interdependence: measuring stock market comovements. The Journal of Finance 57(5), 2223-2261.

Franses, P. and A. Lucas (1998). Outlier detection in cointegration analysis. Journal of Business $8 \mathcal{6}$ Economic Statistics, 459-468.

Guembel, A. and O. Sussman (2009). Sovereign debt without default penalties. Review of Economic Studies 76(4), 1297-1320.

Gupta, A. (2003). Multivariate skew-t distribution. Statistics 37(4), 359-363.

Harvey, A. (2010). Exponential Conditional Volatility Models. working paper.

Haugh, D., P. Ollivaud, and D. Turner (2009, July). What drives sovereign risk premiums? an analysis of recent evidence from the euro area. OECD Economics Department Working Papers 718, OECD Publishing. 
Hilscher, J. and Y. Nosbusch (2010). Determinants of sovereign risk: Macroeconomic fundamentals and the pricing of sovereign debt. Review of Finance 14(2), 235-262.

Hu, W. (2005). Calibration Of Multivariate Generalized Hyperbolic Distributions Using The EM Algorithm, With Applications In Risk Management, Portfolio Optimization And Portfolio Credit Risk. Ph. D. thesis.

Huang, X., H. Zhou, and H. Zhu (2009). A framework for assessing the systemic risk of major financial institutions. Journal of Banking and Finance 33, 2036-2049.

Hull, J. C. and A. White (2000). Valuing credit default swaps i: No counterparty default risk. The Journal of Derivatives 8, 29-40.

Hull, J. C. and A. White (2004). Valuation of a cdo and an nth-to-default cds without monte carlo simulation. Journal of Derivatives 12(2).

Li, D. (2001). On default correlation: a copula function approach. Journal of Fixed Income 9, 43-54.

Longstaff, F., J. Pan, L. Pedersen, and K. Singleton (2011). How sovereign is sovereign credit risk? American Economic Journal: Macroeconomics 3(2), 75-103.

McNeil, A. J., R. Frey, and P. Embrechts (2005). Quantitative Risk Management: Concepts, Techniques and Tools. Princeton University Press.

Mencía, J. and E. Sentana (2005). Estimation and testing of dynamic models with generalized hyperbolic innovations. CEPR Discussion Paper No. 5177.

O'Kane, D. (2008). Modelling Single-Name and Multi-Name Credit Derivatives. Wiley Finance.

Pan, J. and K. Singleton (2008). Default and recovery implicit in the term structure of sovereign CDS spreads. The Journal of Finance 63(5), 2345-84.

Patton, A. and D. H. Oh (2012). Modelling dependence in high dimensions with factor copulas. working paper. 
Patton, A. and D. H. Oh (2013). Time-varying systemic risk: Evidence from a dynamic copula model of cds spreads. working paper.

Patton, A. J. (2006). Modelling asymmetric exchange rate dependence. International Economic Review 47 (2), 527-556.

Reuters (2012). Industry group finds greek deal triggers cds payout. Reuters report, March 92012.

Segoviano, M. A. and C. Goodhart (2009). Banking stability measures. IMF Working Paper.

Smith, M. S., Q. Gan, and R. J. Kohn (2012). Modeling dependence using skew $t$ copulas: Bayesian inference and applications. Journal of Applied Econometrics 27(3), 500-522.

Tirole, J. (2012). Country solidarity, private sector involvement and the contagion of sovereign crises. mimeo.

Wessel, D. (2013). How jawboning works. Wall Street Journal, January 9.

Yue, V. (2010). Sovereign default and debt renegotiation. Journal of International Economics $80(2), 176-187$.

Zettelmeyer, J., C. Trebesch, and G. M. Gulati (2012). The greek debt exchange: An autopsy. working paper.

Zhang, X., D. Creal, S. Koopman, and A. Lucas (2011). Modeling dynamic volatilities and correlations under skewness and fat tails. TI-DSF Discussion paper 11-078/DSF22.

\section{Appendix: Technical Background}

The Generalized Autoregressive Score model of Creal et al. (2011, 2013) for the GH skewed- $t$ (GHST) conditional density (2) adjusts the time-varying parameter $f_{t}$ at every step using the scaled score of the conditional density at time $t$. This can be regarded as a steepest ascent improvement of the parameter using the local (at time $t$ ) likelihood fit of the model.

We partition $f_{t}$ as $f_{t}=\left(f_{t}^{D}, f_{t}^{R}\right)$ for the (diagonal) matrix $D_{t}^{2}=D\left(f_{t}^{D}\right)^{2}$ of variances and correlation matrix $R_{t}=R\left(f_{t}^{R}\right)$, respectively, where $\Sigma_{t}=D_{t} R_{t} D_{t}=\Sigma\left(f_{t}\right)$. We set $f_{t}^{D}=\ln \left(\operatorname{diag}\left(D_{t}\right)\right)$, which ensures that variances are always positive, irrespective of the value of $f_{t}^{D}$. For the correlation matrix, we use the hypersphere parameterization also used in Creal et al. (2011) and Zhang et al. 
(2011). This ensures that $R_{t}$ is always a correlation matrix, i.e., positive semi-definite with ones on the diagonal. We set $R_{t}=R\left(f_{t}^{R}\right)=X_{t} X_{t}^{\prime}$, with $f_{t}^{R}$ as a vector containing $n(n-1) / 2$ time-varying angles $\phi_{i j t} \in[0, \pi]$ for $i>j$, and

$$
X_{t}=\left(\begin{array}{ccccc}
1 & c_{12 t} & c_{13 t} & \cdots & c_{1 n t} \\
0 & s_{12 t} & c_{23 t} s_{13 t} & \cdots & c_{2 n t} s_{1 n t} \\
0 & 0 & s_{23 t} s_{13 t} & \cdots & c_{3 n t} s_{2 n t} s_{1 n t} \\
0 & 0 & 0 & \cdots & c_{4 n t} s_{3 n t} s_{2 n t} s_{1 n t} \\
\vdots & \vdots & \vdots & \ddots & \vdots \\
0 & 0 & 0 & \cdots & c_{n-1, n t} \prod_{\ell=1}^{n-2} s_{\ell n t} \\
0 & 0 & 0 & \cdots & \prod_{\ell=1}^{n-1} s_{\ell n t}
\end{array}\right),
$$

where $c_{i j t}=\cos \left(\phi_{i j t}\right)$ and $s_{i j t}=\sin \left(\phi_{i j t}\right)$. The dimension of $f_{t}^{R}$ thus equals the number of correlation pairs.

As implied by equation (6), we take the derivative of the log conditional density with respect to $f_{t}$, and obtain

$$
\begin{aligned}
\nabla_{t} & =\frac{\partial \operatorname{vech}\left(\Sigma_{t}\right)^{\prime}}{\partial f_{t}} \frac{\partial \operatorname{vech}\left(L_{t}\right)^{\prime}}{\partial \operatorname{vech}\left(\Sigma_{t}\right)} \frac{\partial \operatorname{vec}\left(L_{t} \mathcal{T}\right)^{\prime}}{\partial \operatorname{vech}\left(L_{t}\right)} \frac{\partial \ln p^{G H}\left(y_{t} \mid L\left(f_{t}\right), \gamma, \nu\right)}{\partial \operatorname{vec}\left(L_{t} \mathcal{T}\right)} \\
& =\Psi_{t}^{\prime} H_{t}^{\prime}\left(w_{t}\left(y_{t} \otimes y_{t}\right)-\operatorname{vec}\left(L_{t} \mathcal{T}^{\prime} L_{t}^{\prime}\right)-\left(1-\frac{\nu}{\nu-2} w_{t}\right)\left(y_{t} \otimes L_{t} \mathcal{T} \gamma\right)\right) \\
& =\Psi_{t}^{\prime} H_{t}^{\prime} \operatorname{vec}\left(w_{t} y_{t} y_{t}^{\prime}-L_{t} \mathcal{T}^{\prime} L_{t}^{\prime}-\left(1-\mu_{\varsigma} w_{t}\right) L_{t} \mathcal{T} \gamma y_{t}^{\prime}\right), \\
\Psi_{t} & =\partial \operatorname{vech}\left(\Sigma_{t}\right) / \partial f_{t}^{\prime}, \\
H_{t} & =\left(L_{t} \mathcal{T} \mathcal{T}^{\prime} L_{t}^{\prime} \otimes L_{t} \mathcal{T}^{\prime} L_{t}^{\prime}\right)^{-1}\left(L_{t} \mathcal{T} \otimes \mathrm{I}\right)\left(\left(\mathcal{T}^{\prime} \otimes \mathrm{I}\right) \mathcal{D}_{n}^{0}\right)\left(\mathcal{B}_{n}\left(\mathrm{I}+\mathcal{C}_{n}\right)\left(L_{t} \otimes \mathrm{I}\right) \mathcal{D}_{n}^{0}\right)^{-1}, \\
w_{t} & =\frac{\nu+n}{2 \cdot d\left(y_{t}\right)}-\frac{k_{(\nu+n) / 2}^{\prime}\left(\sqrt{d\left(y_{t}\right) \cdot \gamma^{\prime} \gamma}\right)}{\sqrt{d\left(y_{t}\right) / \gamma^{\prime} \gamma}},
\end{aligned}
$$

where $k_{a}^{\prime}(b)=\partial \ln K_{a}(b) / \partial b$ is the derivative of the log modified Bessel function of the second kind, $\mathcal{D}_{n}^{0}$ is the the duplication matrix $\operatorname{vec}(L)=\mathcal{D}_{n}^{0} \operatorname{vech}(L)$ for a lower triangular matrix $L, \mathcal{D}_{n}$ is the standard duplication matrix for a symmetric matrix $S \operatorname{vec}(S)=\mathcal{D}_{n} \operatorname{vech}(S), \mathcal{B}_{n}=\left(\mathcal{D}_{n}^{\prime} \mathcal{D}_{n}\right)^{-1} \mathcal{D}_{n}^{\prime}$, and $\mathcal{C}_{n}$ is the commutation matrix, $\operatorname{vec}\left(S^{\prime}\right)=\mathcal{C}_{n} \operatorname{vec}(S)$ for an arbitrary matrix $S$.

To scale the score $\nabla_{t}$, Creal, Koopman, and Lucas (2013) propose the use of powers of the inverse information matrix. The information matrix for the GHST distribution, however, does not have a tractable form. Therefore, we scale by the information matrix of the symmetric Student's $t$ distribution,

$$
\mathcal{S}_{t}=\left\{\Psi_{t}^{\prime}\left(\mathrm{I} \otimes\left(L_{t} \mathcal{T}\right)^{-1}\right)^{\prime}\left[g G-\operatorname{vec}(\mathrm{I}) \operatorname{vec}(\mathrm{I})^{\prime}\right]\left(\mathrm{I} \otimes\left(L_{t} \mathcal{T}\right)^{-1}\right) \Psi_{t}\right\}^{-1},
$$

where $g=(\nu+n) /(\nu+2+n)$, and $G=\mathrm{E}\left[z_{t} z_{t}^{\prime} \otimes z_{t} z_{t}^{\prime}\right]$ for $z_{t} \sim \mathrm{N}(0, \mathrm{I})$. Zhang et al. (2011) demonstrate that this results in a stable model that outperforms alternatives such as the DCC if the data are fat-tailed and skewed.

For parsimony, the dynamics of the correlation parameter $f_{t}^{R}$ follow a similar parameterization as in the DCC model,

$$
f_{t+1}^{R}=\tilde{\omega}\left(1-B_{R}\right) \bar{f}_{R}+A_{R} s_{t}^{R}+B_{R} f_{t}^{R},
$$

where $\tilde{\omega}, A_{R}, B_{R} \in \mathbb{R}$ are scalars, and $\bar{f}_{R}$ is such that $R\left(\bar{f}_{R}\right)$ equals the unconditional correlation matrix of the data. Estimation results showed that $\tilde{\omega}$ was close to 1 in all cases. To further reduce the number of parameters, we therefore set $\tilde{\omega}=1$. All remaining parameters are estimated by maximum likelihood. Inference is carried out by taking the negative inverse Hessian of the log 
likelihood at the optimum as the covariance matrix for the estimator.

Evaluating the GHST density and distribution can be tricky due to the modified Bessel function and various off-setting factors in the conditional density expression (2). We used the built-in modified Bessel function of the Ox programming language of Doornik (2007), except in the far tails. For the far tails and $y_{t}, \gamma \in \mathbb{R}$, we used the expression

$$
e^{b} K_{a}(|b|) \approx \sqrt{\frac{\pi}{2|b|}} e^{b-|b|}\left(1+\frac{4 a^{2}-1}{8|b|}\left(1+\frac{4 a^{2}-9}{16|b|}\right)\right),
$$

for large values $|b|$ with $b=\left(y_{t}-\tilde{\mu}_{t}\right) \gamma / L_{t}$; see Abramowitz and Stegun (1970). This also directly balances the skewness effect in either tail in a numerically stable way. If small values of the argument $|b|$ are of interest, similar expansions exist. 


\section{Earlier Working Papers:}

For a complete list of Working Papers published by Sveriges Riksbank, see www.riksbank.se

Estimation of an Adaptive Stock Market Model with Heterogeneous Agents

2005:177

by Henrik Amilon

Some Further Evidence on Interest-Rate Smoothing: The Role of Measurement Errors in the Output Gap

2005:178

by Mikael Apel and Per Jansson

Bayesian Estimation of an Open Economy DSGE Model with Incomplete Pass-Through

2005:179

by Malin Adolfson, Stefan Laséen, Jesper Lindé and Mattias Villani

Are Constant Interest Rate Forecasts Modest Interventions? Evidence from an Estimated Open Economy

DSGE Model of the Euro Area

by Malin Adolfson, Stefan Laséen, Jesper Lindé and Mattias Villani

Inference in Vector Autoregressive Models with an Informative Prior on the Steady State

by Mattias Villani

Bank Mergers, Competition and Liquidity

by Elena Carletti, Philipp Hartmann and Giancarlo Spagnolo

Testing Near-Rationality using Detailed Survey Data

by Michael F. Bryan and Stefan Palmqvist

Exploring Interactions between Real Activity and the Financial Stance

by Tor Jacobson, Jesper Lindé and Kasper Roszbach

Two-Sided Network Effects, Bank Interchange Fees, and the Allocation of Fixed Costs by Mats A. Bergman

Trade Deficits in the Baltic States: How Long Will the Party Last?

by Rudolfs Bems and Kristian Jönsson

Real Exchange Rate and Consumption Fluctuations follwing Trade Liberalization

by Kristian Jönsson

Modern Forecasting Models in Action: Improving Macroeconomic Analyses at Central Banks

by Malin Adolfson, Michael K. Andersson, Jesper Lindé, Mattias Villani and Anders Vredin

Bayesian Inference of General Linear Restrictions on the Cointegration Space

2005:182

by Mattias Villani

Forecasting Performance of an Open Economy Dynamic Stochastic General Equilibrium Model

by Malin Adolfson, Stefan Laséen, Jesper Lindé and Mattias Villani

Forecast Combination and Model Averaging using Predictive Measures

by Jana Eklund and Sune Karlsson

Swedish Intervention and the Krona Float, 1993-2002

2005:183

by Owen F. Humpage and Javiera Ragnartz

A Simultaneous Model of the Swedish Krona, the US Dollar and the Euro

2005:184

by Hans Lindblad and Peter Sellin

Testing Theories of Job Creation: Does Supply Create Its Own Demand?

2005:185

by Mikael Carlsson, Stefan Eriksson and Nils Gottfries

Down or Out: Assessing The Welfare Costs of Household Investment Mistakes

by Laurent E. Calvet, John Y. Campbell and Paolo Sodini

Efficient Bayesian Inference for Multiple Change-Point and Mixture Innovation Models

by Paolo Giordani and Robert Kohn

Derivation and Estimation of a New Keynesian Phillips Curve in a Small Open Economy

by Karolina Holmberg

Technology Shocks and the Labour-Input Response: Evidence from Firm-Level Data

2005:187

2005:188

by Mikael Carlsson and Jon Smedsaas

Monetary Policy and Staggered Wage Bargaining when Prices are Sticky

by Mikael Carlsson and Andreas Westermark

The Swedish External Position and the Krona

2005:189

$2005: 190$

2005:191

by Philip R. Lane 
Evaluating Microfoundations for Aggregate Price Rigidities: Evidence from Matched Firm-Level Data on

Monetary Policy Trade-Offs in an Estimated Open-Economy DSGE Model

by Malin Adolfson, Stefan Laséen, Jesper Lindé and Lars E. O. Svensson

Flexible Modeling of Conditional Distributions Using Smooth Mixtures of Asymmetric

Student T Densities

by Feng Li, Mattias Villani and Robert Kohn

Forecasting Macroeconomic Time Series with Locally Adaptive Signal Extraction

Risk Premiums and Macroeconomic Dynamics in a Heterogeneous Agent Model

by Ferre De Graeve, Maarten Dossche, Marina Emiris, Henri Sneessens and Raf Wouters

Picking the Brains of MPC Members

by Mikael Apel, Carl Andreas Claussen and Petra Lennartsdotter

Involuntary Unemployment and the Business Cycle

by Lawrence J. Christiano, Mathias Trabandt and Karl Walentin

Housing collateral and the monetary transmission mechanism

by Karl Walentin and Peter Sellin

The Discursive Dilemma in Monetary Policy

by Carl Andreas Claussen and Øistein Røisland

Monetary Regime Change and Business Cycles

by Luca Sala, Ulf Söderström and Antonella Trigari

Density-Conditional Forecasts in Dynamic Multivariate Models by Michael K. Andersson, Stefan Palmqvist and Daniel F. Waggoner

Anticipated Alternative Policy-Rate Paths in Policy Simulations

The Effects of Endogenuos Firm Exit on Business Cycle Dynamics and Optimal Fiscal Policy 


\begin{tabular}{lc}
\hline The Cost of Consumer Payments in Sweden & $2012: 262$ \\
by Björn Segendorf and Thomas Jansson & $2012: 263$ \\
\hline Trade Credit and the Propagation of Corporate Failure: An Empirical Analysis & $2012: 264$ \\
by Tor Jacobson and Erik von Schedvin & $2013: 265$ \\
\hline $\begin{array}{l}\text { Structural and Cyclical Forces in the Labor Market During the Great Recession: Cross-Country Evidence } \\
\text { by Luca Sala, Ulf Söderström and AntonellaTrigari }\end{array}$ & $2013: 266$ \\
\hline Pension Wealth and Household Savings in Europe: Evidence from SHARELIFE & $2013: 267$ \\
by Rob Alessie, Viola Angelini and Peter van Santen & $2013: 268$ \\
\hline Long-Term Relationship Bargaining & \\
by Andreas Westermark & \\
\hline Using Financial Markets To Estimate the Macro Effects of Monetary Policy: An Impact-Identified FAVAR* & \\
by Stefan Pitschner & \\
\hline DYNAMIC MIXTURE-OF-EXPERTS MODELS FOR LONGITUDINAL AND DISCRETE-TIME SURVIVAL DATA \\
by Matias Quiroz and Mattias Villani
\end{tabular}


Sveriges Riksbank

Visiting address: Brunkebergs torg 11

Mail address: se-103 37 Stockholm

Website: www.riksbank.se

SVERIGES Telephone: +468 78700 00, Fax: +46 8210531

RIKSBANK E-mail: registratorn@riksbank.se 